\title{
Southern Ocean Thermocline Ventilation
}

\author{
JEAN-BAPTISTE SALLÉE \\ CSIRO-CMAR/CAWCR, Hobart, Tasmania, Australia \\ KEVIN SPEER \\ Department of Oceanography, The Florida State University, Tallahassee, Florida \\ STEVE RINTOUL \\ CSIRO-CMAR/CAWCR/ACE-CRC, Hobart, Tasmania, Australia \\ S. WIJFFELS \\ CSIRO-CMAR/CAWCR, Hobart, Tasmania, Australia
}

(Manuscript received 5 June 2009, in final form 22 September 2009)

\begin{abstract}
An approximate mass (volume) budget in the surface layer of the Southern Ocean is used to investigate the intensity and regional variability of the ventilation process, discussed here in terms of subduction and upwelling. Ventilation resulting from Ekman pumping is estimated from satellite winds, the geostrophic mean component is assessed from a climatology strengthened with Argo data, and the eddy-induced advection is included via the parameterization of Gent and McWilliams, together with eddy mixing estimates. All three components contribute significantly to ventilation. Finally, the seasonal cycle of the upper ocean is resolved using Argo data.

The circumpolar-averaged circulation shows an upwelling in the Antarctic Intermediate Water (AAIW) density classes, which is carried north into a zone of dense Subantarctic Mode Water (SAMW) subduction. Although no consistent net production is found in the light SAMW density classes, a large subduction of Subtropical Mode Water (STMW) is observed. The STMW area is fed by convergence of a southward and a northward residual meridional circulation. The eddy-induced contribution is important for the water mass transport in the vicinity of the Antartic Circumpolar Current. It balances the horizontal northward Ekman transport as well as the vertical Ekman pumping.

While the circumpolar-averaged upper cell structure is consistent with the average surface fluxes, it hides strong longitudinal regional variations and does not represent any local regime. Subduction shows strong regional variability with bathymetrically constrained hotspots of large subduction. These hotspots are consistent with the interior potential vorticity structure and circulation in the thermocline. Pools of SAMW and AAIW of different densities are found along the circumpolar belt in association with the regional pattern of subduction and interior circulation.
\end{abstract}

\section{Introduction}

Theories about the structure of the thermocline have been widely discussed in the past 50 years using two main models: one assuming an adiabatic thermocline (e.g., Luyten et al. 1983) and one assuming a diapycnally diffusive thermocline (e.g., Robinson and Stommel 1959;

Corresponding author address: Jean-Baptiste Sallée, CSIROCMAR/CAWCR, Castray Esplanade, Hobart 7000, TAS, Australia. E-mail: jbsallee@gmail.com
Welander 1959). Luyten et al. (1983) developed a multilayer model with which they showed that ventilation of the thermocline happens where the isopycnals outcrop at the sea surface. In their zero mixing model, potential vorticity $(\mathrm{PV})$ is set at the surface where the windinduced Ekman convergence pumps water into the thermocline. In this concept of large-scale subtropical subduction, mixed layer convergence and the subsequent subduction have long been regarded as driven primarily by large-scale Ekman pumping. However, models including a representation of the mixed layer have shown 
that subduction can be substantially enhanced by the geostrophic mean flow in the presence of a horizontal mixed layer gradient (Woods 1985). This process, known as lateral induction (Huang 1991), can dominate subduction in regions of large lateral mixed layer gradient (e.g., Woods 1985; Cushman-Roisin 1987; Qiu and Huang 1995; Karstensen and Quadfasel 2002). Tracer budgets and distributions are consistent with the hypothesis that subduction is enhanced by lateral induction (Sarmiento 1983; Jenkins 1982).

The contribution of mesoscale eddies to stratification and ventilation of the thermocline has only been discussed in recent years. Rhines and Young (1982) first pointed out that in a closed gyre, a homogenized pool of PV would emerge owing to synoptic-scale eddies. In addition, Marshall et al. (2002) showed from a laboratory experiment that eddies could have a central role in setting the structure of the thermocline. The subduction experiment in the early 1990s showed some of the first evidence of the role of the mesoscale in the ventilation process, suggesting some departures from the early subduction and ventilation theories that assumed largescale steady oceans. Mesoscale mixing is crucial for the evolution of water mass properties following subduction (Joyce et al. 1998; Joyce and Jenkins 1993). Although PV fluxes generally are associated with mass fluxes, passive tracer distributions and float trajectories have demonstrated how diffusion by small-scale motions can ventilate isopycnals exposed to the surface mixed layer without concurrent formation and export of fluid (Sundermeyer and Price 1998; Ledwell et al. 1998; Robbins et al. 2000). In this study, we focus on the net mass exchange between the mixed layer and the thermocline and do not treat the ventilation by a diffusive process.

Owing to the difficulties of observing mesoscale fluxes over broad scales, the importance of the mesoscale mass flux in the subduction process is still poorly understood. Although subduction due to eddy-induced transport has often been ignored in subduction studies (e.g., Marshall et al. 1993; Qiu and Huang 1995; Karstensen and Quadfasel 2002), recent studies have emphasized its importance in frontal regions (e.g., Follows and Marshall 1994; Naveira-Garabato et al. 2001; Sorensen et al. 2001; Karsten and Marshall 2002).

An alternative to the kinematic approach (volume budget of the mixed layer) to subduction taken in the latter studies is the thermodynamic approach (Marshall and Marshall 1995; Marshall et al. 1999). Here diabatic processes that cause the accumulation of water in a density class are summed to deduce the rate of subduction (e.g., Speer and Tziperman 1992). This thermodynamic approach has been widely used to estimate the subduction rate and assumes the diabatic processes are domi- nated by air-sea buoyancy fluxes and not mixing, for instance, which can be intense in the mixed layer. In the vicinity of the Antarctic Circumpolar Current (ACC) a diagnosis of transport across surface outcrops suggests convergence of water centered on the ACC, associated with subduction of Subantartic Mode Water (SAMW) (Speer et al. 2000; Karsten and Marshall 2002). This must involve a combination of the strong northward Ekman transport and geostrophic transport and be balanced by eddy processes of diffusion and a southward eddyinduced advection. We aim to revisit these components to the extent possible with existing observations.

Because of data from the Argo program, we have, for the first time in the Southern Ocean, access to an accurate month-by-month climatology resolving the seasonal cycle and providing relatively robust estimates of the climatological surface geostrophic flow and mixed layer depth (Sallée et al. 2008a,b; Dong et al. 2008). In addition, the 15 years of the Global Drifter Programs (GDP) recently gave rise to new climatological estimates of eddy activity (Zhurbas and Oh 2004; Rupolo 2007; Sallée et al. 2008 c). Our principal goal is to evaluate the contribution and relative roles of the different terms involved in the mixed layer subduction using a variety of recent data in a kinematic volume budget of the mixed layer.

\section{Background}

\section{a. Subduction rate}

Subduction intensity is the rate by which ventilated fluid is transferred from the ocean surface layer into the interior permanent thermocline. As sketched in Fig. 1, water is only permanently injected directly from the mixed layer to the interior thermocline in winter when the mixed layer is at its deepest. In all other seasons, on average, the water leaving the mixed layer enters an area called the seasonal thermocline, which lies below the instantaneous mixed layer $H$ and above the base of the winter mixed layer $H_{\max }$. In this study, we define the subduction as the rate by which water from the seasonal thermocline (i.e., which has been in recent contact with the atmosphere) enters the permanent thermocline. This subduction across the base of the winter mixed layer can occur year-round. The processes opposing subduction, which transfer fluid from the interior thermocline into the ventilated layer, will be called upwelling in this study. Therefore, in the remainder of this study, upwelling is similar to the term obduction, sometimes used in subduction studies.

Many studies have attempted a kinematic estimation of subduction by computing a mixed layer volume budget. As the volume of the mixed layer is changed only by flow entering or leaving the permanent thermocline 

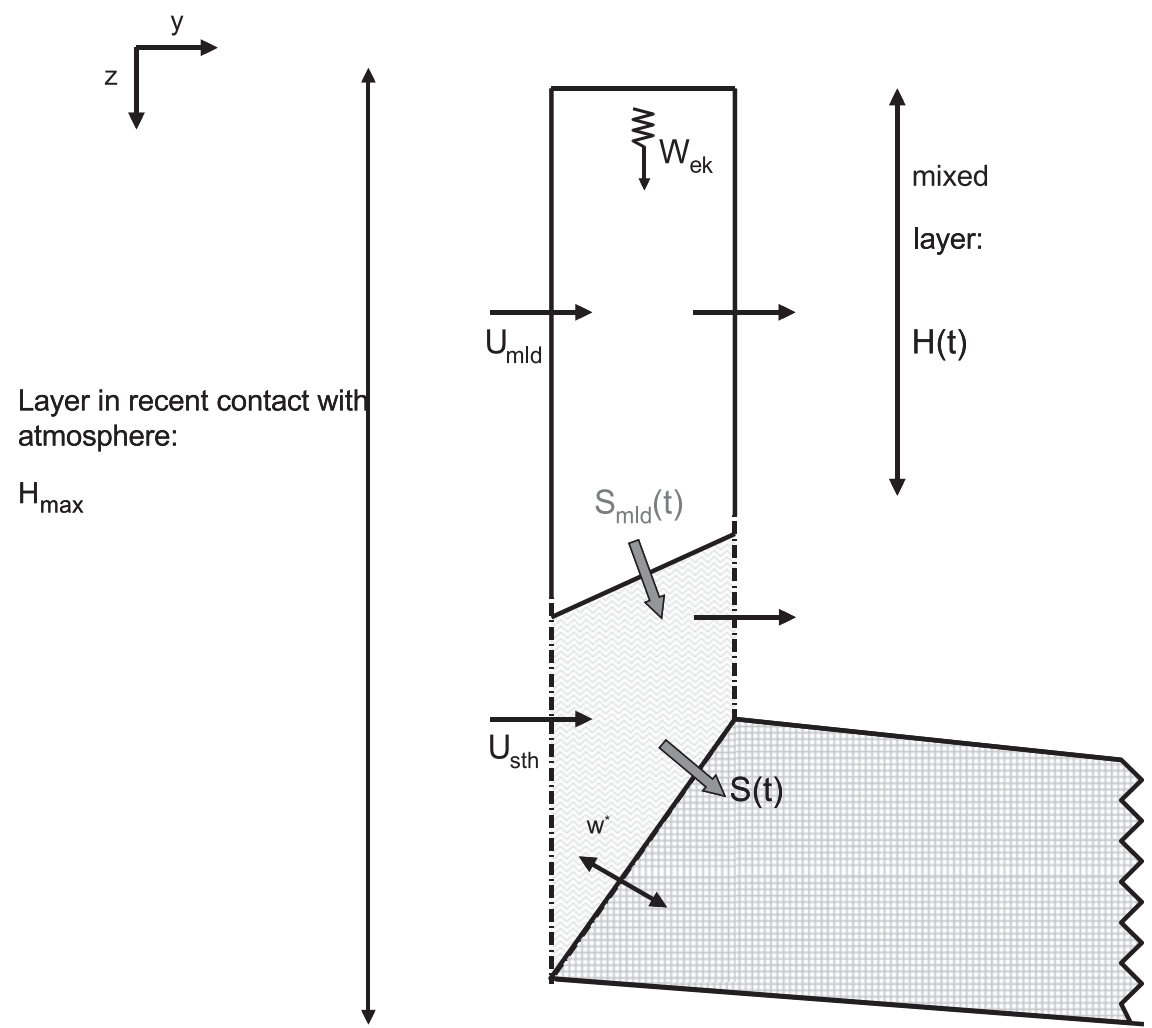

FIG. 1. Schematic of the upper layer of the ocean. The mixed layer depth $H(t)$ seasonally varies to reach its maiximum, $H_{\max }$, in winter. The water leaving the instantenous mixed layer enters the seasonal thermocline (this layer can be considered to have been in recent contact with the atmosphere). The subduction of interest is the water permanently leaving the seasonal thermocline, i.e., the water crossing the surface $z=H_{\text {max }}$. Light (dark) gray shading shows the seasonal (permanent) thermocline; $U_{\mathrm{mld}}$ and $U_{\text {sth }}$ are the horizontal geostrophic velocities in the mixed layer and in the seasonal thermocline respectively; $S_{\mathrm{mld}}(t)$ and $S(t)$ are the rate at which the water crosses the base of the mixed layer and the base of the winter mixed layer respectively; $w_{\mathrm{Ek}}$ is the Ekman pumping and $w^{*}$ is the vertical velocity induced by eddies.

or converging laterally from the surrounding mixed layer, ${ }^{1}$ the volume budget of the mixed layer is written (Cushman-Roisin 1987) as

$$
S_{\mathrm{ml}}(t)=\frac{\partial H}{\partial t}+\nabla\left(\int_{0}^{H} \mathbf{u}\right),
$$

where $S_{\mathrm{ml}}$ is the rate by which water crosses the mixed layer base $\left(\mathrm{m} \mathrm{s}^{-1}\right.$, a positive subduction being a flux into the mixed layer), $\mathbf{u}$ is the velocity in the mixed layer, $H(x, y, t)$ the depth of the mixed layer, and $\nabla$ the twodimensional horizontal divergence operator.

As we are interested only in the water that permanently leaves the mixed layer, we estimate the subduction of water into the permanent thermocline by considering the water crossing the base of the winter mixed layer $Z=$ $H_{\text {max }}$. Therefore, similarly to Eq. (1), the subduction is

\footnotetext{
${ }^{1}$ The volume change by evaporation and precipitation at the surface being negligible.
}

$$
S(t)=\frac{\partial H_{\max }}{\partial t}+\nabla\left(\int_{0}^{H_{\max }} \mathbf{u} d z\right) .
$$

The second term on the right-hand side of Eq. (2) becomes

$$
\boldsymbol{\nabla}\left(\int_{0}^{H(t)} \mathbf{u}(t) d z\right)+\nabla\left(\int_{H(t)}^{H_{\max }} \mathbf{u}(t) d z\right) .
$$

We split the velocity between an Ekman component and a geostrophic velocity: $u(t)=u_{\mathrm{Ek}}(t)+u_{g}(t)$. The Ekman flow is assumed to be contained within the mixed layer, which is a sensible assumption in the Southern Ocean where mixed layers are deep. We consider two layers of distinct geostrophic velocity: instantaneous mixed layer geostrophic velocity $u_{\mathrm{ml}}(t)$ and velocity in the seasonal thermocline, between the base of the instantaneous mixed layer and the base of the winter mixed layer $u_{\mathrm{sth}}(t)$. The second term on the right-hand side of Eq. (2) becomes 


$$
\begin{aligned}
\left(\int_{0}^{H_{\max }} \mathbf{u} d z\right)= & \nabla\left(U_{\mathrm{Ek}}\right)+\nabla\left(u_{\mathrm{ml}}(t) H(t)\right) \\
& +\nabla\left[u_{\mathrm{sth}}(t)\left(H_{\max }-H(t)\right)\right],
\end{aligned}
$$

where $U_{\mathrm{Ek}}$ is the Ekman transport. Exploiting the Argo dataset, we resolve the seasonal cycle of the mixed layer and examine the budget for monthly climatological means. Since $H_{\max }$ is fixed over the climatological annual cycle, when averaged over a month Eq. (2) becomes

$$
\begin{aligned}
\bar{S}^{m} & =\nabla\left({\overline{U_{\mathrm{Ek}}}}^{m}\right)+\nabla\left({\overline{u_{\mathrm{ml}}}(t) H(t)}^{m}\right)+\nabla\left({\overline{u_{\mathrm{sth}}(t)\left(H_{\max }-H(t)\right)}}^{m}\right) \\
& =\nabla\left({\overline{U_{\mathrm{Ek}}}}^{m}\right)+\nabla\left[\left({\overline{u_{\mathrm{ml}}}}^{m}+u_{\mathrm{ml}}^{*}\right) \bar{H}^{m}\right]+\nabla\left[\left({\overline{u_{\mathrm{sth}}}}^{m}+u_{\mathrm{sth}}^{*}\right)\left(H_{\mathrm{max}}-\bar{H}^{m}\right)\right],
\end{aligned}
$$

where $\overline{(\cdot)}^{m}$ denotes a climatological monthly average, $(\cdot)_{\mathrm{ml}}$ and $(\cdot)_{\text {sth }}$ refer to mixed layer and seasonal thermocline velocities, and $\mathbf{u}^{*}$ the eddy-induced velocity $\left(\mathbf{u}^{*}=\right.$ ${\overline{\mathbf{u}^{\prime} H^{\prime}}}^{m} / \bar{H}^{m}$, see Gent and McWilliams 1990; see section 2.3 of McDougall 1991). Finally, assessing the divergence of the geostrophic flow from the linear vorticity equation, the monthly mean subduction through the base of the winter mixed layer becomes

$$
\bar{S}^{m}={\overline{S_{\mathrm{Ek}}}}^{m}+{\overline{S_{\text {geo }}}}^{m}+{\overline{S_{\text {eddy }}}}^{m},
$$

where

$$
\begin{aligned}
{\overline{S_{\mathrm{Ek}}}}^{m}= & {\overline{w_{\mathrm{Ek}}}}^{m}, \\
\overline{S_{\mathrm{geo}}^{m}}= & {\overline{\mathbf{u}_{\mathrm{ml}}}}^{\mathbf{m}} \cdot \nabla \bar{H}^{m}+{\overline{\mathbf{u}_{\mathrm{sth}}}}^{\mathbf{m}} \cdot \nabla\left(H_{\mathrm{max}}-\bar{H}^{m}\right) \\
& -\frac{\beta}{f}\left[\bar{H}^{m}{\overline{v_{\mathrm{ml}}}}^{m}+\left(H_{\max }-\bar{H}^{m}\right){\overline{v_{\mathrm{sth}}}}^{m}\right],
\end{aligned}
$$

and

$$
{\overline{S_{\text {eddy }}}}^{m}=\nabla\left[\mathbf{u}_{\mathrm{ml}}^{*} \bar{H}^{m}+\mathbf{u}_{\mathrm{sth}}^{*}\left(H_{\max }-\bar{H}^{m}\right)\right] .
$$

Annual mean subduction is the average of the monthly means.

\section{b. Transport in the upper ocean}

As discussed above, subduction is the convergence of water in the upper ocean (above the base of the winter mixed layer). We examine the transport in the upper ocean to understand better where the water subducted into the ocean interior originates. We define the transport above the winter mixed layer base to be

$\bar{T}^{m}={\overline{\left(\int_{0}^{H_{\max }} \mathbf{u}(t) d z\right)}}^{m}={\overline{U_{\mathrm{Ek}}}}^{m}+{\overline{T_{\text {geo }}}}^{m}+{\overline{T_{\text {eddy }}}}^{m}$,

where

$$
{\overline{T_{\text {geo }}}}^{m}={\overline{\mathbf{u}_{\mathrm{ml}}}}^{m} \bar{H}^{m}+{\overline{\mathbf{u}_{\text {sth }}}}^{m}\left(H_{\mathrm{max}}-\bar{H}^{m}\right)
$$

and

$$
{\overline{T_{\text {eddy }}}}^{m}=\mathbf{u}_{\mathrm{ml}}^{*} \bar{H}^{m}+\mathbf{u}_{\mathrm{sth}}^{*}\left(H_{\max }-\bar{H}^{m}\right) .
$$

The buoyancy budget in the upper ocean is needed to relate the transport to the diabatic processes of the upper ocean (e.g., Marshall 1997; Speer et al. 2000; Karsten and Marshall 2002). The density of the water column above $H_{\max }$ (Fig. 1) can either be modified by air-sea fluxes, lateral mixing and vertical diffusion, or by lateral and vertical advection. Therefore, the transport of buoyancy across a buoyancy surface $b$ is (e.g., Marshall et al 1999)

$$
T(b) \nabla b=B_{\text {surf }}(b)+B_{\text {eddy }}(b)+B_{\text {vertical }}(b),
$$

where $B_{\text {surf }}$ is the air-sea buoyancy flux, $B_{\text {eddy }}$ the lateral eddy buoyancy mixing above $H_{\max }$, and $B_{\text {vertical }}$ the vertical diffusion. We chose to set the vertical diffusion to a constant value of $\kappa_{z}=1.510^{-5} \mathrm{~m}^{2} \mathrm{~s}^{-1}$ [similar to, e.g., Marshall et al. (1999), Karsten and Marshall (2002), and to observations at the base of the mixed layer from Cisewski et al. (2005)]. Then, one can easily relate the subduction calculation to the buoyancy forcing $\left(B_{\text {surf }}+\right.$ $B_{\text {eddy }}+B_{\text {vertical }}$ ). We note that Eq. (8) is expressed in terms of $b$, which undergoes a large seasonal cycle in the mixed layer. We will therefore perform this calculation in monthly averages, which will allow us to follow the seasonal movement of $b$ surfaces.

\section{c. Eddy-induced velocity: $u^{*}$}

The water volume transport in a layer of thickness $h$ and velocity $v$ is $T=v h$. Hence, the monthly mean average transport is

$$
\bar{T}^{m}=\bar{v}^{m} \bar{h}^{m}+{\overline{v^{\prime} h^{\prime}}}^{m},
$$

where the prime denotes an anomaly from the monthly time average. Therefore, in addition to mixing, eddies provide an advection of tracer by the eddy-induced velocity defined here by 


$$
\mathbf{u}^{*}=\frac{{\overline{\mathbf{v}^{\prime} h^{\prime}}}^{m}}{\bar{h}^{m}} .
$$

Following Gent and McWilliams (1990) and Treguier et al. (1997), we parameterize the eddy-induced velocity from the eddy diffusion coefficient and the interior isopycnal structure:

$$
\mathbf{u}^{*}= \begin{cases}\frac{\partial}{\partial z}\left[\kappa \nabla \bar{b}^{m} / \bar{b}_{z}^{m}\right]=\frac{\partial}{\partial z}\left[\kappa \overline{\mathbf{s}}^{m}\right], & \text { below the mixed layer } \\ {\left[\kappa \overline{\mathbf{s}}^{\mathbf{m}}\right]_{z=H} \frac{\partial \mu(z)}{\partial z},} & \text { in the mixed layer }\end{cases}
$$

in which $\kappa$ is the eddy diffusion coefficient, $b$ is the buoyancy in the ocean, and $\mathbf{s}$ is the slope of the isopycnals (i.e., $\bar{s}^{m}=\nabla \bar{b}^{m} /{\overline{b_{z}}}^{m}$ ). Here $\mu(z)$ is a function smoothly decaying from one at the base of the mixed layer to zero at the surface, which is used to spread the horizontal eddy-induced mass transport occurring below the mixed layer through the entire mixed layer.

Therefore, the monthly averaged eddy-induced velocity in the mixed layer and in the seasonal thermocline becomes

$$
\begin{aligned}
& u_{\mathrm{ml}}^{*}=\frac{1}{\bar{H}^{m}} \int_{0}^{\bar{H}^{m}}\left[\kappa \overline{\mathbf{s}}^{m}\right]_{z=H} \frac{\partial \mu(z)}{\partial z} d z, \\
& u_{\mathrm{sth}}^{*}=\frac{1}{H_{\text {max }}-\bar{H}^{m}} \int_{\bar{H}^{m}}^{H_{\max }} \frac{\partial}{\partial z}\left[\kappa \overline{\mathbf{s}}^{m}\right] d z .
\end{aligned}
$$

Consequently, we find from Eqs. (6) and (7):

$$
\begin{aligned}
& {\overline{S_{\text {eddy }}}}^{m}=\boldsymbol{\nabla} \cdot\left[\kappa \overline{\mathbf{s}}^{m}\right]_{z=H_{\max }} ; \\
& {\overline{T_{\text {eddy }}}}^{m}=\left[\kappa \overline{\mathbf{s}}^{m}\right]_{z=H_{\text {max }}} .
\end{aligned}
$$

\section{Data and methods}

We estimate the annual mean transport $\bar{T}$ in the layer above the winter mixed layer base [Eq. (7)] and the annual mean subduction $\bar{S}$ from this layer [Eq. (6)]. Annual means are derived from monthly estimates that we compute from the datasets described in this section. We need monthly estimates of mixed layer depth, interior density structure, geostrophic circulation, and eddy diffusion. We also need estimates of wind stress and air-sea buoyancy fluxes.

\section{a. Mixed layer depth and interior density structure}

The vertical structure of the Southern Ocean is determined from the combination of two distinct datasets: the Argo float database and the ship-based Southern Ocean database (SODB) (available online at http://woceSOatlas. tamu.edu for more information). The Argo project con- tributes about half of the Southern Ocean profiles, fills in the center of ocean basins, and completes sampling during the austral winter (Sallée et al. 2008b). We use only profiles that have passed the Argo real-time quality control containing information on their position, date, temperature $T$, and salinity $S$ profiles. Most Argo profiles sample $T$ and $S$ from the surface to 2000-m depth every 10 days.

We calculated the mixed layer depth for every Southern Ocean profile with a surface density difference criterion $\Delta \sigma_{\theta} \leq 0.03 \mathrm{~kg} \mathrm{~m}^{-3}$ (Sallée et al. 2006; Dong et al. 2008) and mapped monthly averages by a Loess fitting method (Ridgway et al. 2002). The extensive coverage provided by the Argo datasets allows us to get monthly maps of mixed layer depth on half-degree grids with error estimates. Figure 2a shows the annual mean mixed layer depth in the Southern Ocean. Deep mixed layers are found directly north of and within the ACC. The ACC regions are represented by the mean position of its three main fronts: the Polar Front (PF), the Subantarctic Front (SAF), and the northern branch of the Subantarctic Front (SAF-N) using the Sallée et al. (2008b) definitions. The mixed layer depth pattern is in accordance with previous studies (Hanawa and Talley 2001; de Boyer Montégut et al. 2004; Sallée et al. 2008a; Dong et al. 2008). No deep mixed layer is found in the South Atlantic Ocean or in the western south Indian Ocean. Then, a rapid transition to a thicker layer occurs at about $70^{\circ} \mathrm{E}$ as the flow passes the Kerguelen Plateau. The mixed layer depth reaches a maximum in the eastern Indian Ocean and south of Australia; after that the very deep mixed layer shoals as the flow rounds the Campbell Plateau, and these shallower mixed layers continue up to the Eltanin Fracture Zone in the mid Pacific Ocean $\left(220^{\circ} \mathrm{E}\right)$. A second maximum with deep mixed layers is found in the eastern Pacific basin, before it shoals rapidly through Drake Passage. This large-scale pattern of mixed layer depth is consistent with a simplified winter heat budget considering the Ekman and air-sea fluxes and is strongly influenced by local eddy heat mixing (Sallée et al. 2006, 2008a). To estimate error, the mapping 
a)

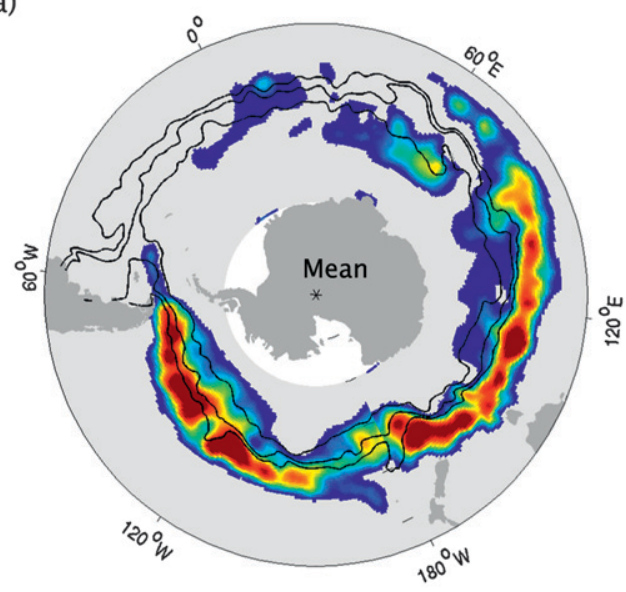

b)

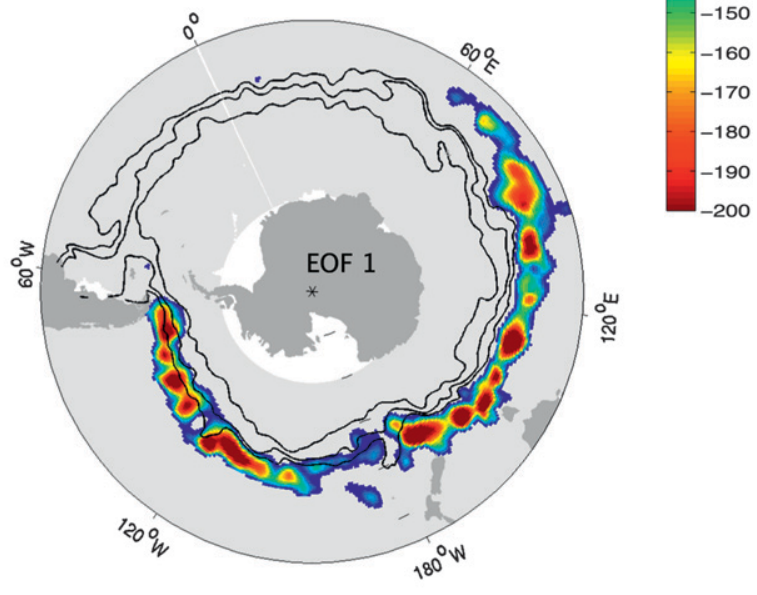

c)

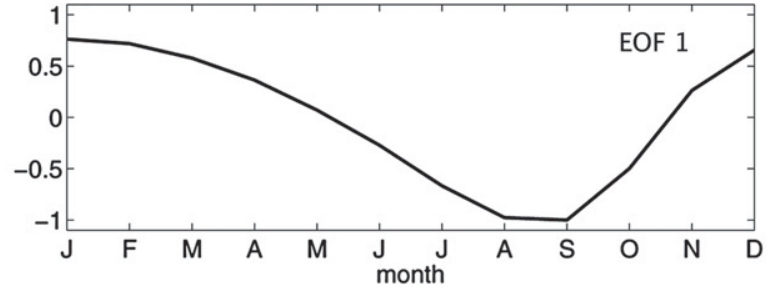

FIG. 2. (a) Annual mean depth of the mixed layer and (b),(c) the first EOF mode showing the seasonal cycle ( $88 \%$ of the total variance)

of mixed layer depth has been performed 100 times with datasets for which we randomly removed $30 \%$ of the Argo datasets. The standard deviation of the 100 maps is an estimation of the mapping error. The maximum error is found in deep mixed layer areas and is $O(50 \mathrm{~m})$ in winter in these zones.

The deep mixed layer areas are subject to strong seasonal variability. Figure $2 b$ shows the first empiricval orthogonal function mode of variability of the mixed layer depth deduced from monthly climatological means. This mode accounts for $\sim 88 \%$ of the mixed layer depth variability in the Southern Ocean and clearly represents the seasonal cycle. The deep mixed layer areas have a sawtooth seasonal cycle with variations up to $500 \mathrm{~m}$. Slow destratification starts in January and reaches its maximum nine months later in September, whereas the restratification is much faster, taking only three months.

\section{b. Geostrophic mean circulation}

We infer the long-term mean dynamic field and the geostrophic circulation of the Southern Ocean from the Argo and SODB datasets described above, selecting the $T-S$ profiles defined between 10 and $1500 \mathrm{~m}$ to produce a database of the surface dynamic height referenced to $1500 \mathrm{~m}$. We assessed the sampling and mapping errors of this field from a similar Monte Carlo experiment as for the mixed layer depth. We found a typical standard error of $1 \%$ of the dynamic height field. The $1500-\mathrm{m}$ reference level was chosen as the best compromise between the deepest possible level and including a maximum of data profiles. Assuming no motion at the 1500-m level implies that we neglect the barotropic mean flow and the mean baroclinic flow below $1500 \mathrm{~m}$. To assess the impact of this assumption, we also computed our calculations from an absolute mean dynamic height product developed by Rio et al. (2005). This product mixes satellite data from the Gravity Recovery and Climate Experiment (GRACE) and altimetry with in situ data from GDP. Its mean fields include both barotropic and baroclinic components.

Geostrophic circulation on isopycnals is analyzed in this study using the Montgomery streamfunction (Montgomery 1937; McDougall 1989): $\Psi_{M}=p \delta-\int \delta d p$, where $p$ is the pressure and $\delta$ is the specific volume anomaly. We note, however, that this streamfunction is an approximation, neglecting the variations of specific anomaly along the isopycnal surface: no exact streamfunction on an isopycnal exists.

\section{c. Eddy diffusion coefficient}

A climatological surface cross-stream eddy diffusivity coefficient has been estimated in bins of $5^{\circ}$ longitude by $1^{\circ}$ latitude for the Southern Ocean by Sallée et al. (2008c). This coefficient results from a statistical formulation, computed using 10 years (1995-2005) of surface drifter data. On average over the circumpolar belt, the diffusivity shows an increase from the Antarctic continent to the ACC, a stable plateau around $4000 \mathrm{~m}^{2} \mathrm{~s}^{-1}$ within the ACC, and a further increase north of the ACC dominated by the western boundary current regions (standard error of $1 \%$ and a standard deviation of $28 \%$ ). The intensity of this coefficient is on the higher side of the range of surface diffusion coefficient estimates. For example, Marshall et al. (2006) found much smaller values of surface diffusion with a plateau in the ACC 
around $1000 \mathrm{~m}^{2} \mathrm{~s}^{-1}$. The large range of diffusion coefficients estimates that exists in the literature comes from the use of different methods. Indeed, studies resolving the jets of the ACC have tended to show a reduction of the surface diffusion coefficient in the ACC and an enhancement at depth (Smith and Marshall 2009; Abernathey et al. 2010; Naveira-Garabato et al. 2009, manuscript submitted to J. Phys. Oceanogr.). Although Sallée et al. (2008c) do not resolve the jets, they still represent the only local estimates of a diffusion coefficient in the Southern Ocean, and applying their coefficient with error bars is the best that we can do at present.

In addition, it has been shown that the high surface diffusion coefficient better represents the mixing in a coarse-resolution mixed layer model (Vivier et al. 2010). Recent modeling studies suggest that surface intensified diffusivity as large as $4000 \mathrm{~m}^{2} \mathrm{~s}^{-1}$ improves the simulation of the eddy-induced advection in the upper ocean (Danabasoglu and Marshall 2007). Finally, Ferreira et al. (2005) suggested that a high diffusion coefficient (up to $9000 \mathrm{~m}^{2} \mathrm{~s}^{-1}$ at the surface) is needed in their coarseresolution residual mean ocean circulation model to minimize the departure from ocean observations. These model studies at coarse resolution suggest that the ocean surface is highly diffusive, in good agreement with Sallée et al.'s (2008c) coefficient estimated on a coarse-resolution grid. To better understand the impact of the choice of mixing coefficient on the subduction and on the surface layer transport, we will also use two others: one constant surface value of $4000 \mathrm{~m}^{2} \mathrm{~s}^{-1}$ as in Danabasoglu and Marshall (2007) and one similar to that of Marshall et al. (2006), that is, a constant value of $2000 \mathrm{~m}^{2} \mathrm{~s}^{-1}$ outside the ACC and $1000 \mathrm{~m}^{2} \mathrm{~s}^{-1}$ within the ACC. The Marshall et al. coefficient is a circumpolar integrated estimate, which suggests much lower surface diffusion than Sallée et al. (2008c). Although an extension of their study providing regional estimates of diffusion shows closer values to Sallée et al. (2008c; see Shuckburgh et al. 2009), we will use the Marshall et al. coefficient to test low coefficients.

The diffusion coefficient $\kappa$ is assumed to be vertically constant in the mixed layer. Following Ferreira et al. (2005), we parameterized the vertical variability of $\kappa$ below the mixed layer from its surface value using the vertical variability of the Brunt-Väisälä frequency $N^{2}$ :

$$
\kappa(z)=\kappa_{\text {baseML }} \frac{N^{2}(z)}{N_{\text {baseML }}^{2}},
$$

where $\kappa_{\text {baseML }}$ and $N_{\text {baseML }}^{2}$ are the eddy diffusion coefficient and the Brunt-Väisälä frequency at the base of the mixed layer.

\section{d. Wind stress and air-sea fluxes}

We estimate the Ekman transport and Ekman pumping using the Quick Scatterometer Mean Wind Field (QuickSCAT MWF) gridded product [this global halfdegree-resolution product is processed and distributed by the Centre European Remote Sensing Satellite (ERS) d'Archivage et de Traitement (CERSAT); available online at http://www.ifremer.fr/cersat/]. We used weekly maps of wind stress between 2003 and 2007 to produce monthly mean maps over a period consistent with the Argo data. The stated error of the product is less than $7 \times 10^{-3} \mathrm{~Pa}$ over the area studied.

The buoyancy flux $B_{\text {surf }}$ is deduced from the heat flux (HF) and the freshwater flux (FWF):

$$
B_{\text {surf }}=g \frac{\alpha}{\rho_{0} C_{p}} \mathrm{HF}+g \beta S \mathrm{FWF},
$$

where $\alpha$ and $\beta$ are the thermal expansion and saline contraction coefficients and $S$ the surface salinity.

The buoyancy flux field remains poorly known in the Southern Ocean. In this study we decided to consider three widely used estimates of air-sea fluxes. We first used a databased estimate: the National Oceanography Centre (NOC) adjusted climatology (Grist and Josey 2003). This climatology is based on in situ data and bulk formulas. The heat fluxes are adjusted using an inverse technique to remove any global ocean heat budget imbalance. We also used two reanalysis products: the National Centers for Environmental Prediction/Department of Energy Global Reanalysis 2 (NCEP-2) (available online at http://www. cdc.noaa.gov) and the Japanese 25-yr reanalysis (JRA-25; available online at http://jra.kishou.go.jp). We averaged the monthly fields of these reanalyses over the period 2002-08 to get monthly climatological fields consistent with the Argo time frame.

\section{Transport in the surface layer and subduction}

\section{a. Meridional transport in the surface layer}

In this section we present results integrated along potential density contours at the base of the winter mixed layer. Figure 3a shows the annual mean across-isopycnal flow. The strong westerlies blowing all around the circumpolar belt in the Southern Ocean drive a northward Ekman transport. This transport toward lighter densities reaches a maximum of $33 \mathrm{~Sv}\left(\mathrm{~Sv} \equiv 10^{6} \mathrm{~m}^{3} \mathrm{~s}^{-1}\right)$ across the 26.9- $\sigma_{\theta}$ isopycnal, at the dense side of the SAMW density class (Hanawa and Talley 2001; Sallée et al. 2008a). It carries a large amount of cold water, which destabilizes the mixed layer and forms SAMW (Speer et al. 2000; Rintoul and England 2002; Sallée et al. 2008a). 


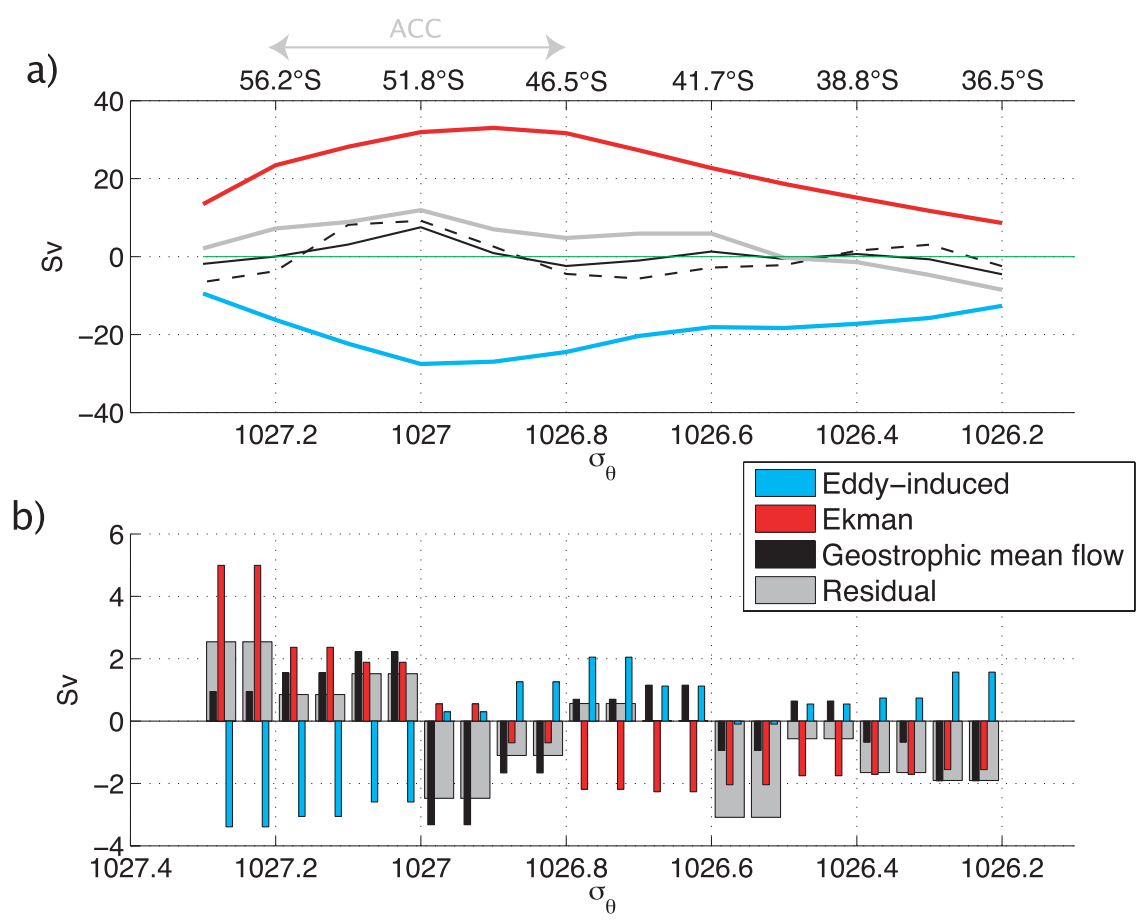

FIG. 3. (a) Annual mean transport (Sv) in the upper layer (above the winter mixed layer depth) across isopycnals and averaged along winter mixed layer isopycnal contours (positive values show a transport toward lighter water). Ekman transport (red), mean geostrophic transport (black), and eddy-induced transport (cyan) are shown along with the residual transport (gray). The mean geostrophic transport computed from Rio et al. (2005) is also displayed (dashed black). (b) Annual mean irretrievable subduction (across the winter mixed layer depth) averaged along winter mixed layer isopycnal contours. Colors as in (a).

Consistent with previous studies, we find that the eddyinduced flow transports water toward the south and tends to compensate the northward Ekman flow (e.g., Speer et al. 2000; Karsten and Marshall 2002; Marshall and Radko 2003). Its intensity is largest in the vicinity of the ACC where isopycnals are steepest. As with the northward Ekman transport, the southward eddy flow reaches its maximum within the ACC and is weaker to the south and the north of the ACC. This maximum is reached across the 26.8-27- $\sigma_{\theta}$ isopycnal range, where the flow carries approximately $27 \mathrm{~Sv}$ toward the south. Averaged along isopycnals, the eddy-induced and Ekman transports closely compensate each other, the residual being $\pm 5 \mathrm{~Sv}$.

The near-surface residual circulation has often been computed in a streamline framework where the mean geostrophic flow across streamlines is by construction zero (e.g., Karsten and Marshall 2002). However, when looking at water mass formation the picture cannot be simply translated from a streamline to a density coordinate. Indeed, the mean geostrophic transport across isopycnals has an order one role in the overall picture (see Fig. 3a). The mean geostrophic transport in the mixed layer crosses isopycnals, especially when the ACC interacts with bathymetry or with western boundary currents (Fig. 4). For example, when the Agulhas Retroflection merges with the ACC in the central Indian basin near the Kerguelen Plateau $\left(70^{\circ} \mathrm{E}\right)$, the mixed layer density in the current increases from 26.3 to $26.7 \sigma_{\theta}$. When the the ACC is steered to the south by the Southwest Indian Ridge $\left(\sim 100^{\circ}-140^{\circ} \mathrm{E}\right)$, the mixed layer transport increases to densities around $26.8 \sigma_{\theta}$. The current shifts south as it rounds the Campbell Plateau, after which the mixed layer density spreads over a large range of isopycnals between 26.9 and $27.2 \sigma_{\theta}$. Lighter waters are introduced into the ACC by the western boundary current of the South Pacific subtropical gyre rounding New Zealand (Sallée et al. 2008b). As the flow crosses the fracture zones in the central Pacific $\left(\sim 120^{\circ}-\right.$ $130^{\circ} \mathrm{W}$ ), it moves southward and crosses the $27-\sigma_{\theta}$ isopycnals. In the eastern Pacific, as the flow passes through Drake Passage, it reaches a density of approximately $27.1 \sigma_{\theta}$. The main part of the surface layer in the ACC evolves from dense to light in the Atlantic Ocean; however, the associated transport is weaker, as the mixed layer in the Atlantic sector is shallower (Fig. 2). 


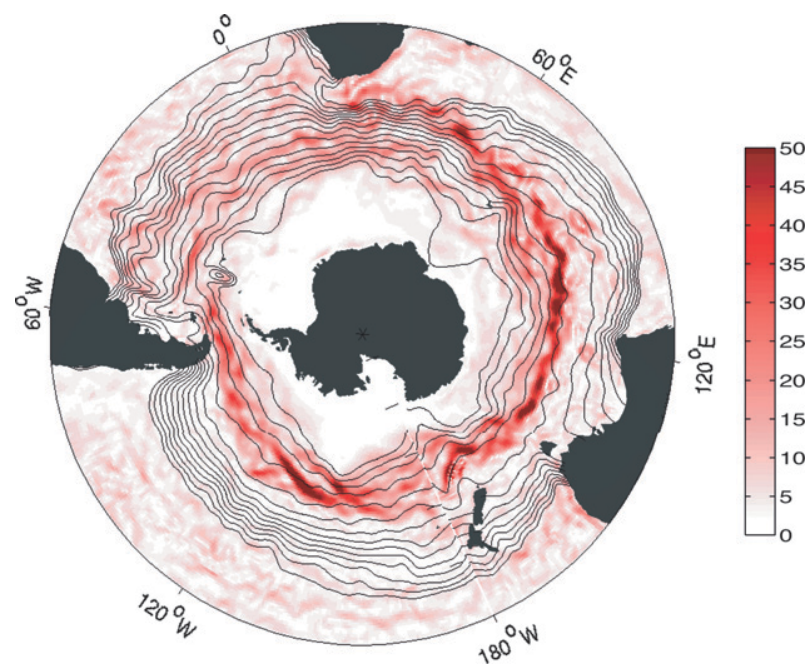

FIG. 4. Absolute value of the geostrophic mean transport intensity $\left(\mathrm{m}^{2} \mathrm{~s}^{-1}\right)$ in the mixed layer of the Southern Ocean. Superimposed are the mixed layer density contours from 26 to $27.3 \sigma_{\theta}$ every $0.1 \mathrm{~kg} \mathrm{~m}^{-3}$.

Consequently, we observe a significant mixed layer geostrophic transport across isopycnals along the circumpolar belt, especially in the density range of the ACC (see Fig. 3a). The total transport in the mixed layer is northward across isopycnals greater than $26.5 \sigma_{\theta}$ and southward across lighter densities. The northward transport reaches a maximum of $12 \mathrm{~Sv}$ at $27 \sigma_{\theta}$ and is responsible for convergence and divergence of water in the Antarctic Intermediate Water (AAIW) and SAMW density class.

As explained in section $3 \mathrm{~b}$, we use a mean flow referenced at $1500 \mathrm{~m}$, ignoring any barotropic and deep baroclonic flow. To estimate the impact of such an assumption, we compared our results with a calculation using an absolute geostrophic mean flow from Rio et al. (2005). As shown in Fig. 3a, results are very similar.

\section{b. Subduction}

Subduction is deduced from the convergence and divergence of water in the mixed layer [Eq. (6)]. Figure 3b shows the subduction in the Southern Ocean averaged in isopycnal bins.

Ekman pumping upwells waters denser than $27 \sigma_{\theta}$ and subducts lighter waters. The upwelling is at its highest around $27.3 \sigma_{\theta}$, whereas the largest subduction is around $26.7 \sigma_{\theta}$. Consistent with previous studies, we find that Ekman pumping contributes to the subduction of SAMW and STMW and upwells AAIW.

The eddy-induced vertical velocity compensates the Ekman component by convergence in water denser than $27 \sigma_{\theta}$ on the southern side of the ACC. Lighter waters are upwelled by the eddy-induced velocity, the strongest upwelling being centered $\sim 26.7-26.8 \sigma_{\theta}$. We find that the eddy-induced subduction plays an order one role in the overall subduction picture in the Southern Ocean. It tends to counteract Ekman upwelling on AAIW and to remove water from SAMW classes.

Interestingly, Karstensen and Quadfasel (2002) found that the eddy-induced transport plays only a minor role in the mixed layer-thermocline exchange. They assessed the eddy-induced contribution by inferring the subduction from a kinematic method that neglects the eddies and from a water age approach, which includes all components; however, their error bars are big. Indeed, they use the very smooth World Ocean Atlas 1998 (Levitus et al. 1998) in the kinematic approach. Also, the water age approach is based on a few lines of the World Ocean Circulation Experiment (WOCE), and their subduction estimate is affected by neglected mixing processes. They refer to these errors in their study, and consequently conclude that the difference they find is negligible and does not reflect eddy-induced processes; however, part of this difference could be due to such processes. We note that they find an overall reduction of downwelling over their outcrop area when they estimate it with the water age approach. This would be consistent with a reduction of subduction by eddy-induced processes over their outcrop area. As their outcrop area covers mostly the SAMW and STMW area, this appears to be consistent to some degree with our results (Fig. 3a).

As mentioned earlier, the geostrophic mean flow also plays an important role in the convergence/divergence of water in the surface layer. Water denser than $27 \sigma_{\theta}$ is carried to lower density and the flow tends to subduct water around 26.8-27 $\sigma_{\theta}$. In lighter layers, no consistent upwelling or subduction shows up.

The net subduction can be summarized as follows (gray bars in Fig. 3b): $\sim 10 \mathrm{~Sv}$ of water upwells in the 2727.3- $\sigma_{\theta}$ density class (AAIW) and is then transported northward toward the SAMW density class. We then observe a subducted $7 \mathrm{~Sv}$ of dense SAMW (26.8-27 $\left.\sigma_{\theta}\right)$, fed from the south by upwelled AAIW. In light SAMW layers (26.6-26.8 $\left.\sigma_{\theta}\right)$ no consistent subduction or upwelling is observed. We observe $14 \mathrm{~Sv}$ of STMW subduction (26.2-26.6 $\sigma_{\theta}$ ), fed by a convergence of the residual meridional circulation from both south and north. In section 5 , we tackle the regional departure from these circumpolarly integrated results, but before this, we test the consistency of this picture with respect to different eddy activity estimates and with the thermodynamic estimate of the subduction.

\section{c. Sensitivity to the diffusion coefficient}

An uncertain parameter in our calculation is the eddy diffusion coefficient $\kappa$, used in the calculation of the 

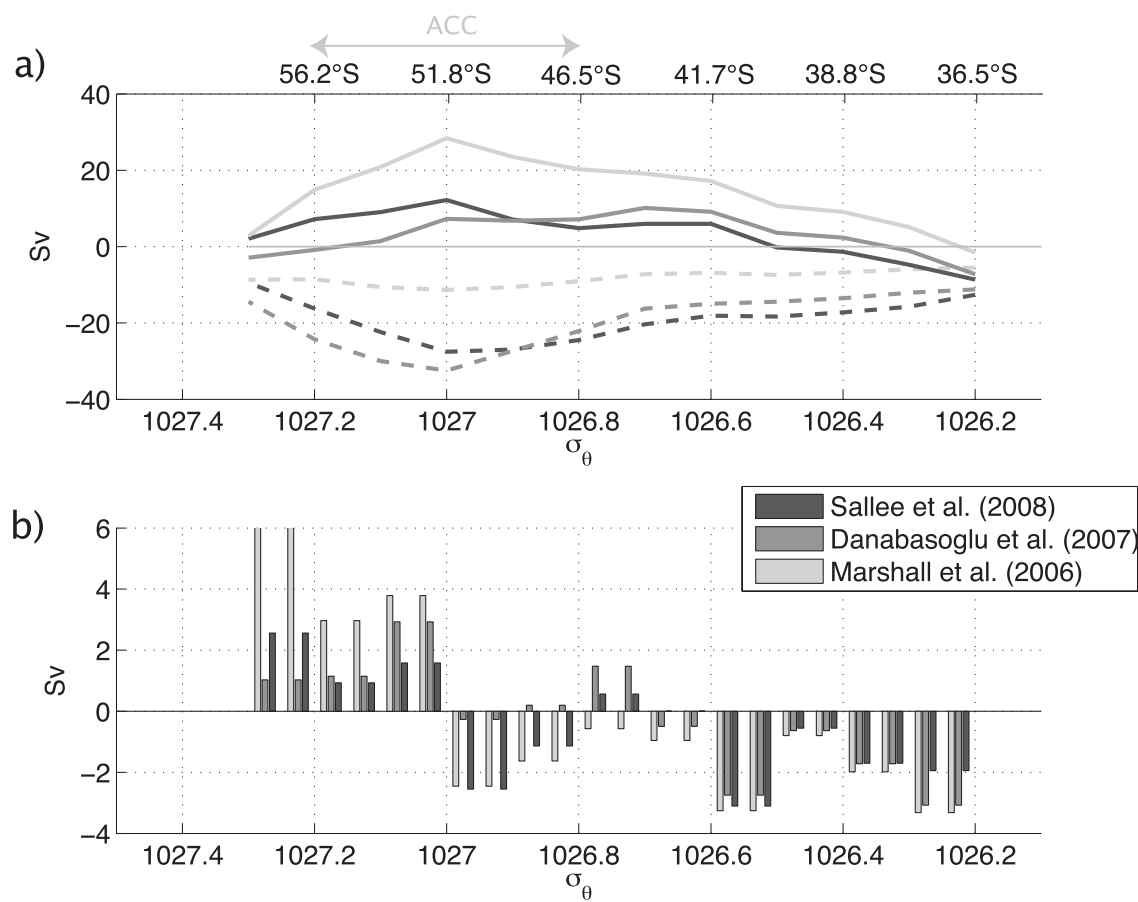

FIG. 5. As in Fig. 3, but for (a) only the eddy-induced transport (dashed lines) and the residual transport (solid lines), and (b) the subsequent subduction are shown. The eddy-induced component has been computed with three different estimations of $\kappa$ : [from Sallée et al. (2008c), Danabasoglu and Marshall (2007) and Marshall et al. (2006)].

eddy-induced flow. Recent observational studies have provided different results concerning the magnitude of the eddy diffusivity in the Southern Ocean (e.g., Marshall et al. 2006; Sallée et al. 2008c; Shuckburgh et al. 2009). In our study we chose to use the Lagrangian drifter-based estimate from Sallée et al. (2008c). Here, we aim to quantify the impact of this choice on the subduction picture. To do so, we compute our calculations with two other surface coefficients: one similar to the Marshall et al. (2006) estimate of average diffusivity, which is at the lower range of diffusion estimates, and one similar to the constant coefficient from Danabasoglu and Marshall (2007).

Choice of the coefficient substantially impacts the meridional circulation (Fig. 5a). Indeed, a small coefficient such as from Marshall et al. (2006), gives rise to a residual transport strongly dominated by the northward Ekman transport. In contrast, coefficients from Danabasoglu and Marshall (2007) and Sallée et al. (2008c) are both associated with stronger southward transport. Despite these large differences, the convergence/divergence associated with the residual circulation is, in fact, very close for each of the three cases. Figure 5b shows the associated subduction for each of the three diffusion cases. The lowdiffusion case (Marshall et al.'s 2006 coefficient) upwells more AAIW, although the Danabasoglu and Marshall (2007) coefficient subducts less SAMW and AAIW.
However, the general shape of the subduction in each isopycnal bin is similar for any of these three scenarios and supports the resulting distribution of subduction. These results show that the subduction is not very sensitive to large-scale change of the surface diffusion coefficient. However, local change of surface diffusion would probably affect the subduction more by creating a local gradient of surface transport. A suite of recent studies has suggested a possible reduction of diffusion coefficient in the core of the ACC jets (Smith and Marshall 2009; Abernathey et al. 2010; Naveira-Garabato et al. 2009, manuscript submitted to J. Phys. Oceanogr.). These jetscale drops of diffusion could affect the subduction in the vicinity of the ACC.

\section{d. Thermodynamic approach}

Equation (8) links the surface layer transport to the surface buoyancy forcing, providing an opportunity to test the consistency of our surface layer transport calculation with a thermodynamic approach. Although often neglected, horizontal mixing can contribute to the buoyancy forcing and should be included in upper-cell studies (Treguier et al. 2007; Sallée et al. 2008a). Here we parameterized its impact from an eddy diffusion coefficient and consider mixing only in the mixed layer (Sallée et al. 2008c). 
a)

$\mathrm{ACC} \quad$ kinematics
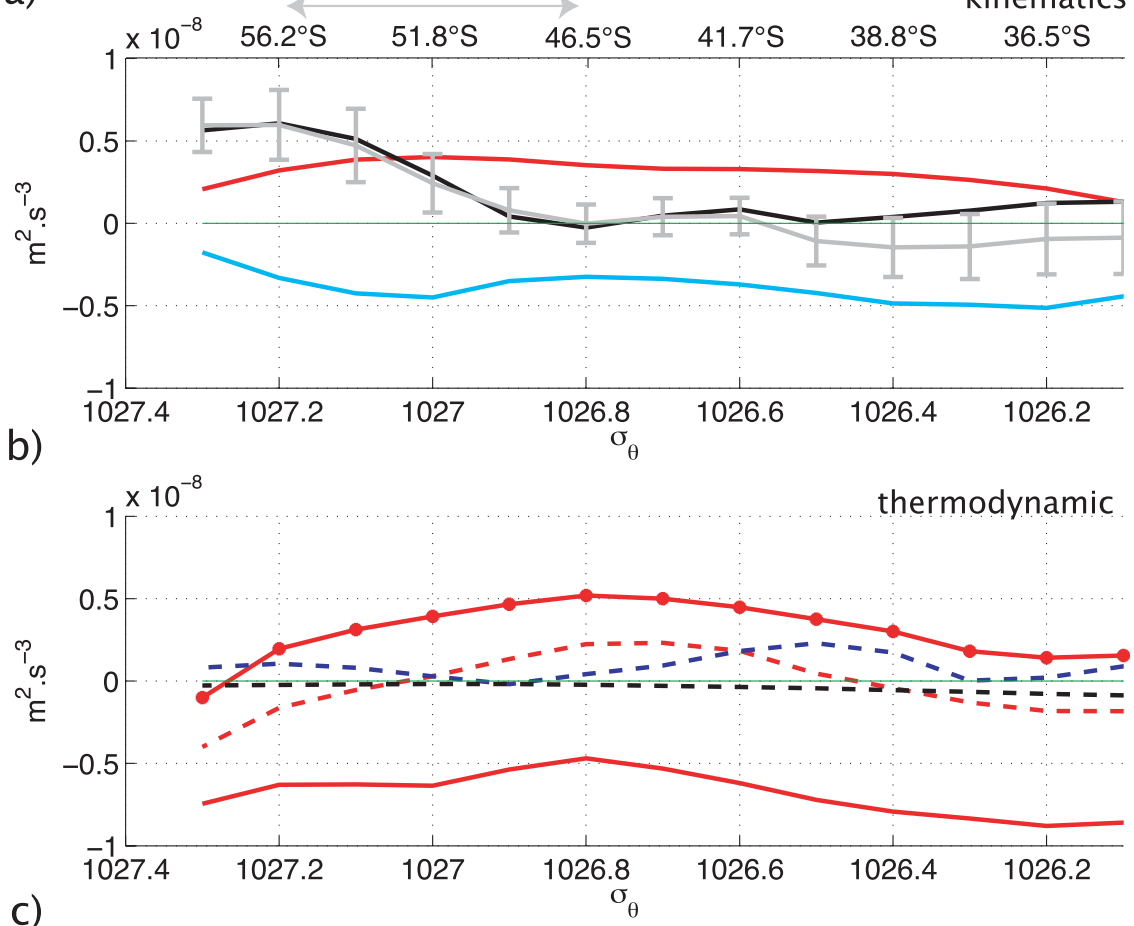

c)

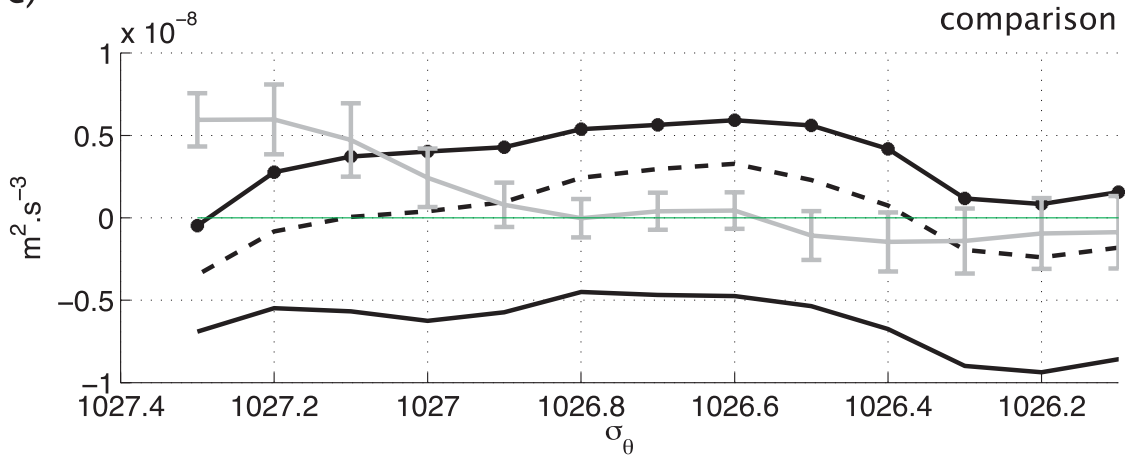

FIG. 6. (a) Annual mean mixed layer buoyancy transport $\left(\mathrm{m}^{2} \mathrm{~s}^{-3}\right)$ across isopycnals, averaged along winter mixed layer isopycnal contours (positive values show a transport toward lighter water). The Ekman buoyancy transport (red), the geostrophic mean transport (black), the eddy-induced transport (cyan), and the residual transport (gray) are shown. The standard error resulting from along-isopycnal averaging of the residual transport is superimposed. (b) Annual mean air-sea buoyancy flux averaged along winter mixed layer isopycnal contours from JRA-25 (red dashed), NCEP-2 (red dots), and NOC readjusted (solid red). Buoyancy flux from eddy mixing (blue) and vertical diffusion (black) are also shown. (c) The total mixed layer buoyancy transport and its standard error from (a) is shown (thick-gray curve). Superimposed are the buoyancy forcings $\left(\overline{B_{\text {surf }}}\right.$ annual $+{\overline{B_{\text {eddy }}}}^{\text {annual }}+\overline{B_{\text {vertical }}}{ }^{\text {annual }})$ estimated from JRA-25 (black dashed), NCEP-2 (black dots), and NOC-readjusted (solid black) air-sea fluxes.

Air-sea buoyancy flux products show large differences in the Southern Ocean. Therefore, we use three independent products: NOC-adjusted, NCEP-2 reanalysis, and JRA-25 reanalysis. The buoyancy transport in the mixed layer is shown in Fig. 6a. It is in fact similar to Fig. 3a but transformed into density coordinates. We also show the standard error of the near-surface residual bouyancy transport arising from along-isopycnal averaging [assuming an arbitrary $10^{\circ}$ of zonal decorrelation scale, consistent with Gille (2003)].

The annual mean thermodynamics transformation of water is shown in Fig. 6b. The three air-sea buoyancyforcing products show large discrepencies. The NOCadjusted forcing suggests a loss of heat in all densities, 
whereas the NCEP-2 suggests a gain of heat. Mixing provides buoyancy on the light side of the strong gradients (north) and extracts buoyancy on the dense side (south). However, the averaging over the year, with isopycnal meridionally moving owing to the mixed layer seasonal cycle, tends to smooth out this frontal effect. We detect a buoyancy gain signal on the dense side of the ACC (around $27.2 \sigma_{\theta}$ ) and the western boundary currents (around $26.4 \sigma_{\theta}$, Fig. 6b). Vertical diffusion has a negligible impact on the buoyancy. However, large uncertainties remain on the vertical diffusion coefficient, and we note that the vertical diffusion becomes significant in the lightest density range when considering a coefficient $\kappa_{z}$ of $O\left(10^{-4} \mathrm{~m}^{2} \mathrm{~s}^{-1}\right)$.

The residual buoyancy forcing has a quite large envelope due to the discrepancy in the air-sea forcing (Fig. 6c). However, a general shape is obtained, with two maxima of buoyancy loss centered on 26.2 and $27.2 \sigma_{\theta}$. Although the thermodynamic and kinematics results do not match exactly, they agree within the buoyancy forcing envelope. We note that some inconsistencies between the two approaches come from the different ocean surface temperature used in the present study and in the atmospheric reanalaysis products. A comparison between the analyzed SST in JRA-25 and the surface temperature from Argo floats suggests large discrepencies, a maximum south of the ACC, around $27.3 \sigma_{\theta}$, where we consistently find the weakest agreement between the thermodynamic and kinematic calculations.

A qualitative regional comparison of the air-sea buoyancy forcing and the buoyancy transport estimated from the kinematic approach is presented in Fig. 7. We show the buoyancy transport from which we removed the lateral mixing by eddies and vertical diffusion $\left(\bar{T}^{\text {annual }} \nabla b\right.$ $-\bar{B}_{\text {eddy }}$ annual $-\bar{B}_{\text {vertical }}$ annual , where $\overline{(\cdot)}$ annual refers to an annual mean carefully computed following the seasonal cycle of the mixed layer density field) and we compare it to the air-sea product $\left(\overline{B_{\text {surf }}}{ }^{\text {annual }}\right)$. We heavily smoothed the results (over $5^{\circ}$ of longitude and latitude) to the typical spatial scale resolved by the reanalysis products.

As above, we observed large discrepancies between the three estimates of surface fluxes. However, these three air-sea products show a large loss of buoyancy in the western Indian Ocean and a small buoyancy gain or reduced buoyancy loss in the Pacific basin. The air-sea buoyancy fluxes needed to sustain our subduction calculation thus show two key large-scale features. Our results are qualitatively consistent with the three air-sea products considered and imply realistic values of buoyancy flux. The analysis shows that not all of the products are necessarily in agreement.

\section{Regional variability}

\section{a. Maps of subduction}

The circumpolar integrated results presented above suggest an overall upwelling of AAIW and downwelling of dense SAMW. In this section, we investigate the regional variability of the subduction and show that the circumpolar integrated picture mixes regional regimes and hides areas of intense subduction.

Ekman pumping has a near-zonal contribution to the subduction with downwelling vertical velocity north of the ACC and upwelling south of the ACC (Fig. 8a). This is consistent with previous studies that showed the ACC core position is related to a zero wind stress curl contour (e.g., Chelton et al. 2004; Karstensen and Quadfasel 2002).

We divided the geostrophic contribution into two pieces: the vertical velocity due to geostrophy [beta advection term $\left.w_{z}=(\beta / f) v H\right]$ and the lateral induction $(u \nabla H)$. The vertical velocity makes only a small contribution to the subduction. The lateral induction term is larger and induces velocities up to $200 \mathrm{~m} \mathrm{yr}^{-1}$. Strong convergence is found in the Indian and Pacific western basins where boundary currents flow southward and merge with the ACC in the middle of the basins (near Kerguelen at $70^{\circ} \mathrm{E}$ and near the fracture zone at $220^{\circ} \mathrm{E}$ ). Before merging, these intense flows pass through a deepening mixed layer in the subantarctic zone (see Fig. 2a), which tends to bring water into the mixed layer (i.e., upwelling).

Large areas of subduction are found in the subtropical gyre, north of the western boundary currents, and north of the ACC in the central and eastern basins. Figure 9a shows the meridional mixed layer depth gradient along with the surface geostrophic streamfunctions. North of the intense currents, we observe branches of circulation leaving the core of the ACC to circulate in the subantarctic zone (especially near $60^{\circ}-70^{\circ} \mathrm{E}, 130^{\circ} \mathrm{E}$, and $\left.120^{\circ}-140^{\circ} \mathrm{W}\right)$. These branches flow through shoaling mixed layers and consequently tend to push water out of the mixed layer. Similarly, in Drake Passage the ACC flows through a sharply shoaling mixed layer (Fig. 2), which induces intense downwelling.

Large subduction is also observed where the ACC shifts slightly toward the south away from the deep mixed layer. For example, in the eastern Indian Ocean (around $110^{\circ} \mathrm{E}$ ), the southeastern Indian Ridge steers the ACC to flow southward across a mixed layer area, deepening toward the north. Even if the southward shift is subtle, the mixed layer gradient is sharp and the velocity is intense in the ACC core; hence a large subduction is induced on the southern edge of this deep mixed layer pool (Fig. 9). Similar downwelling is observed as the ACC is steered south in the eastern Pacific (around $100^{\circ} \mathrm{W}$ ). 
a)

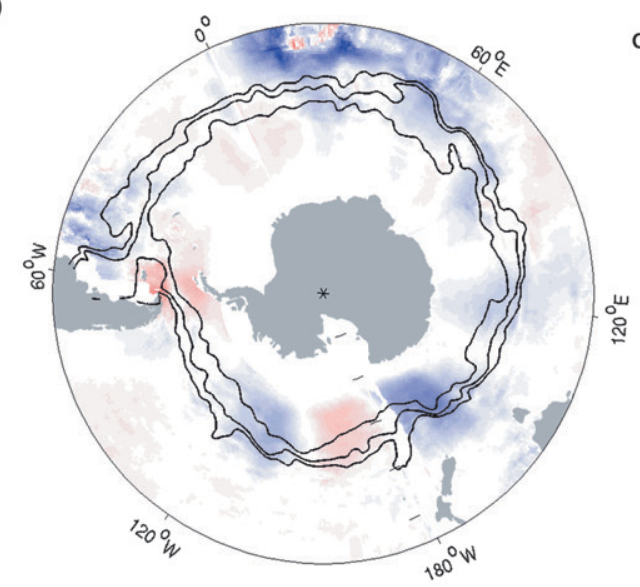

b)

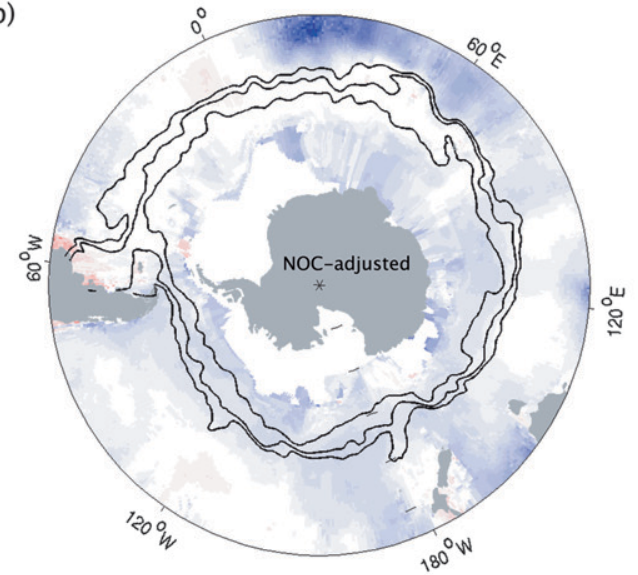

c)

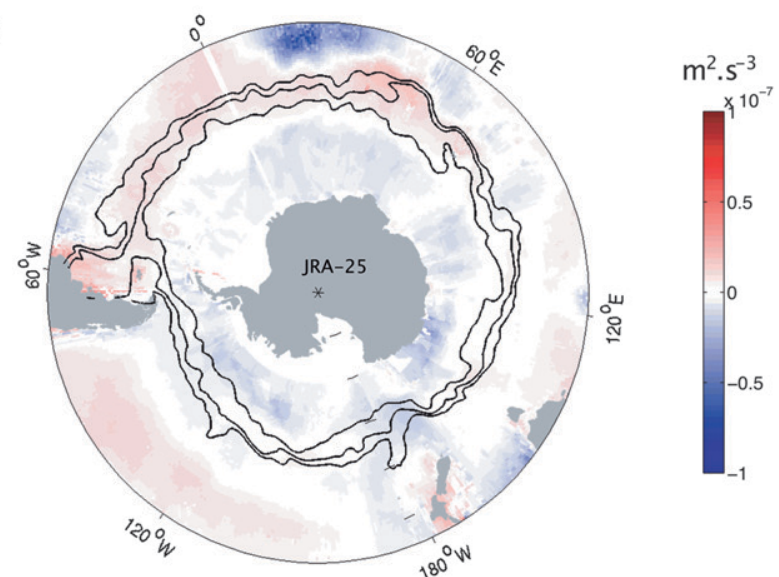

d)

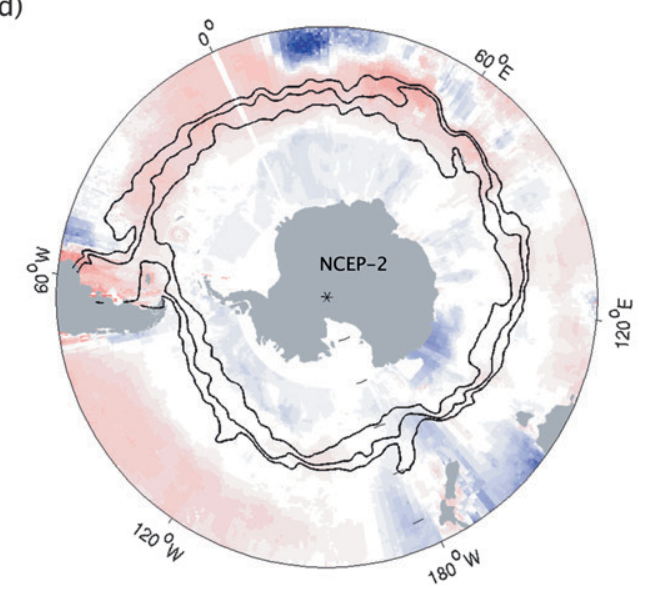

FIG. 7. (a) Annual mean buoyancy transport in the surface layer minus the eddy buoyancy mixing and vertical mixing contributions. (b) Climatological annual mean air-sea buoyancy fluxes from NOC adjusted. (c) Climatological air-sea buoyancy fluxes from JRA-25. (d) Climatological air-sea buoyancy fluxes from NCEP-2. Heat removed (added) from the ocean is blue (red).

The eddy-induced mixed layer-thermocline exchange is locally intense, reaching values up to $100 \mathrm{~m} \mathrm{yr}^{-1}$ (Fig. 8d). The regional pattern matches well with the ACC meridional position, with upwelling north of the fronts and downwelling south of the fronts. Because the frontal area in the ACC is a zone of steep isopycnals, it then corresponds to the strongest southward eddyinduced flow, according to the Gent and McWilliams 


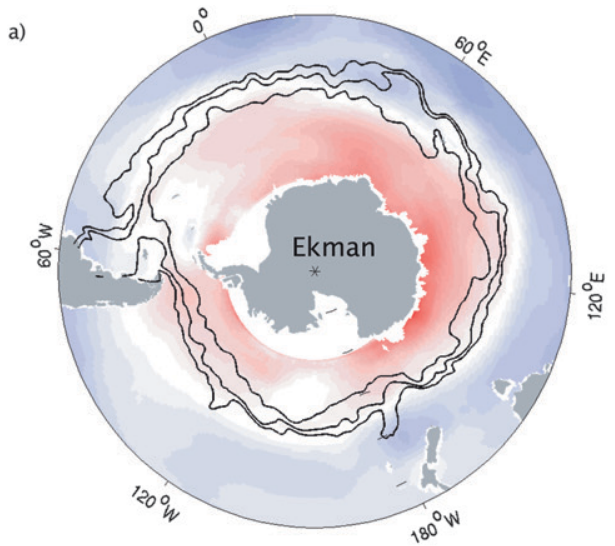

b)
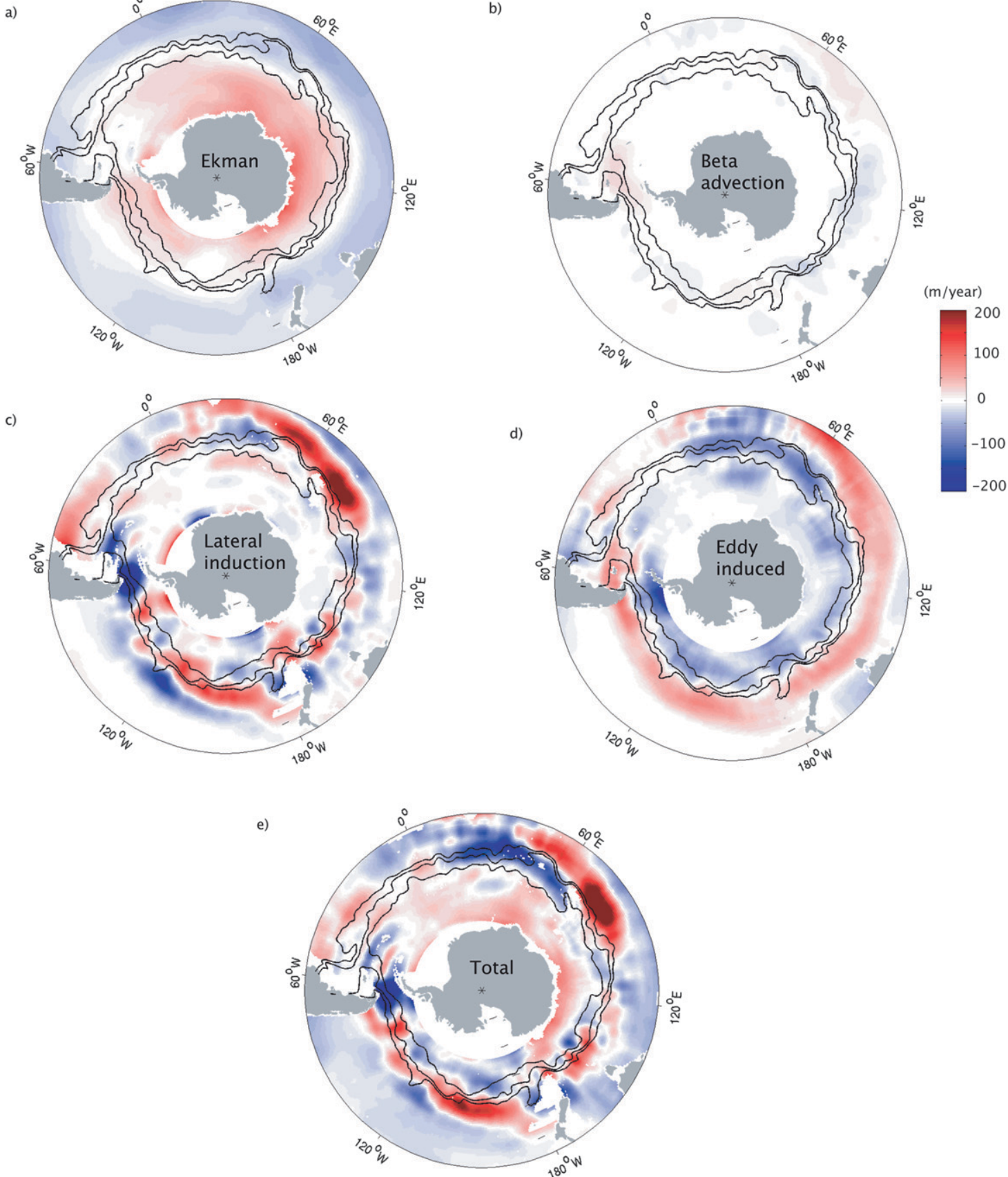

FIG. 8. Maps of the different componenents of annual mean subduction ( $\left.\mathrm{m} \mathrm{yr}^{-1}\right)$ from Eq. (6): (a) vertical Ekman velocity, (b) vertical velocity due to geostophic flow (beta advection), (c) lateral induction by mean geostrophic flow, (d) eddy-induced subduction, and (e) total annual mean subduction. Superimposed are the three main fronts of the ACC: PF, SAF and SAF-N, from Sallée et al. (2008b). Positive values are associated with upwelling.

(1990) parameterization [Eq. (11)]. Therefore, a divergence of mass is created north of the ACC and a convergence south of the ACC, as illustrated in Fig. 8d.

Strong subduction due to eddies is also observed within and north of the frontal area in the western Indian basin. In this basin the intense Agulhas retroflection dominates the circulation and the isopycnal slope, so the convergence/divergence is shifted north, centered on this western boundary current.

The total mixed layer-thermocline exchange (the sum of Ekman, mean geostrophic, and eddy-induced subduction) shows some large-scale features (Fig. 8e). 
a)

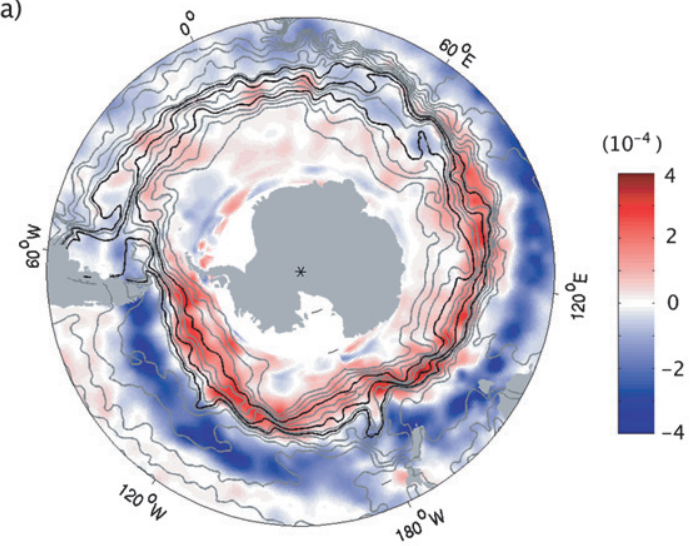

b)

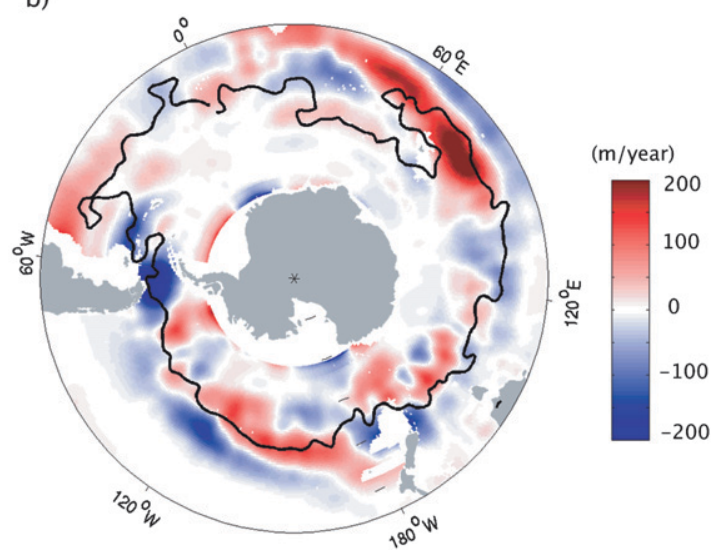

FIG. 9. (a) Meridional gradient of winter mixed layer depth (positive denotes northward deepening of the mixed layer). Superimposed are the mean streamlines at the ocean surface from Argo [black lines being the three main fronts of the ACC: PF, SAF and SAF-N, from Sallée et al. (2008b)]. (b) Zero contour of the winter mixed layer depth meridional gradient superimposed on the subduction rate due to lateral induction.

Large-scale upwellings, mainly due to lateral induction, are observed in the western and central basins north of the ACC in the Indian and Pacific Oceans. Elsewhere north of the ACC, we observe several subduction areas produced by lateral induction resulting from branches of circulation leaving the ACC core. Strong downwelling occurs when the ACC hits the shoaling mixed layer around the Campbell Plateau $\left(170^{\circ} \mathrm{E}\right)$ and in Drake Passage. Lateral induction by geostrophic mean flow on the southern edge of the deep mixed layer pool dominates the mixed layer-thermocline exchanges in the eastern Indian and Pacific basins $\left(120^{\circ} \mathrm{E}\right.$ and $\left.90^{\circ} \mathrm{W}\right)$. Eddies dominate the subduction within the ACC core in the western Indian basin and south of the ACC in the Pacific basin. Finally, away from the ACC, Ekman pumping dominates with downwelling water on the northern side and upwelling water on the southern side.

We estimated the error associated with these upwelling/downwelling structures from the datasets' stated errors and the mapping and sampling errors described in section 3. We found median errors of $33 \mathrm{~m} \mathrm{yr}^{-1}$ for the Ekman pumping, $27 \mathrm{~m} \mathrm{yr}^{-1}$ for the geostrophic mean lateral induction, and $25 \mathrm{~m} \mathrm{yr}^{-1}$ for the eddy-induced vertical velocity. This implies a total error of $85 \mathrm{~m} \mathrm{yr}^{-1}$ for the subduction, but the general structure of the mixed layer-thermocline exchange remains within this error limit and is fairly well defined.

\section{b. Subduction along isopycnals}

A display of subduction in density classes along the circumpolar belt illustrates the strong regional variability. We chose three density classes, the light SAMW: 26.7$26.8 \sigma_{\theta}$; the dense SAMW: 26.9-27 $\sigma_{\theta}$; and the AAIW: 27.1-27.2 $\sigma_{\theta}$. Subduction patterns are clearly controlled by the large bathymetry features of the Southern Ocean (Fig. 10): the Kerguelen Plateau $\left(70^{\circ} \mathrm{E}\right)$, the Campbell Plateau $\left(170^{\circ} \mathrm{E}\right)$, the Eltanin Fracture Zone $\left(220^{\circ} \mathrm{E}\right.$, $\left.140^{\circ} \mathrm{W}\right)$, and Drake Passage $\left(290^{\circ} \mathrm{E}, 70^{\circ} \mathrm{W}\right)$.

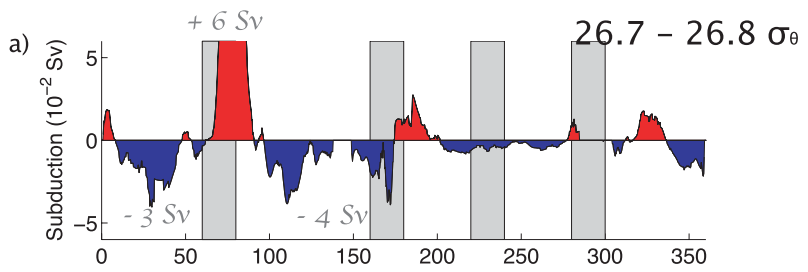

b)
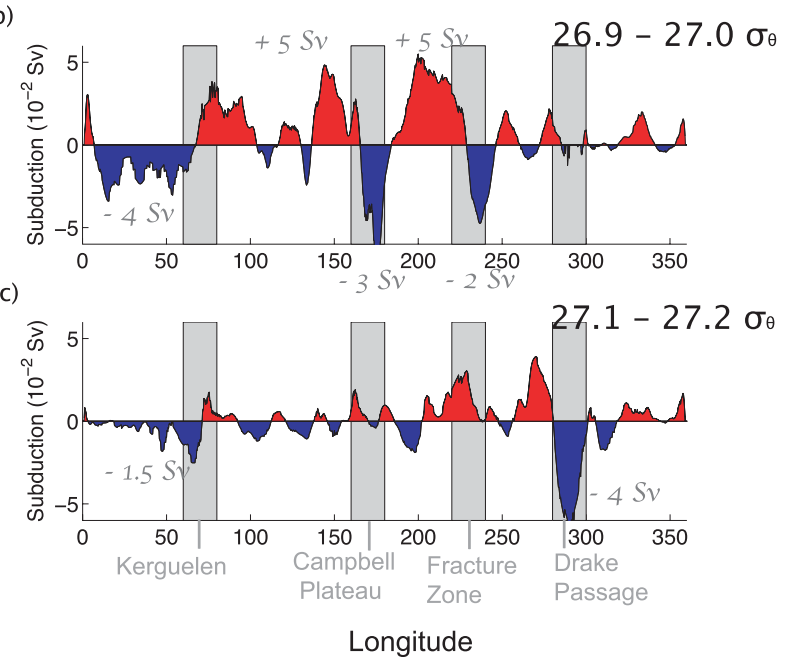

FIG. 10. Subduction along the circumpolar belt in the density range (a) 26.7-26.8 $\sigma_{\theta}$, (b) 26.9-27 $\sigma_{\theta}$, and (c) 27.1-27.2 $\sigma_{\theta}$. Gray bars show the position of the main bathymetric structures along the circumpolar belt: the Kerguelen Plateau $\left(70^{\circ} \mathrm{E}\right)$, the Campbell Plateau $\left(170^{\circ} \mathrm{E}\right)$, the Eltanin Fracture Zone $\left(230^{\circ} \mathrm{E}\right)$, and Drake Passage $\left(290^{\circ} \mathrm{E}\right)$. 
Hotspots of subduction are found in the western Indian Ocean for the three density classes considered here. These hotspots are dominated by an eddy-induced transport convergence south of the intense Agulhas retroflection. Away from the western Indian Ocean, subduction in each density class occurs at a preferred site. Whereas light SAMWs downwells mostly in the eastern Indian Ocean ( $\sim 4 \mathrm{~Sv}$, Fig. 10a), dense SAMWs subduct as the ACC rounds the Campbell Plateau ( $\sim 3 \mathrm{~Sv}$, Fig. 10b) and passes through the Eltanin Fracture Zone ( $\sim 2$ Sv, Fig. $10 \mathrm{~b})$. Consistent with previous studies, we find that the AAIW density class water enters the permanent thermocline mostly in Drake Passage ( 4 Sv, Fig. 10c).

Near the Kerguelen Plateau light SAMW strongly upwells $(\sim 6 \mathrm{~Sv})$ into the mixed layer. The dense SAMW upwells both in the eastern Indian Ocean $(\sim 5 \mathrm{~Sv})$ and in the western Pacific $(\sim 5 \mathrm{~Sv})$. Because of these strong upwelling regions, the net vertical velocity around the circumpolar belt is positive (i.e., upwelling) in the SAMW density class (Fig. 3b). However, this net upwelling is actually composed of large downwelling and upwelling variability. If the subducted water stays close to the base of the mixed layer and is advected downstream, it is likely to be reabsorbed by upwelling. In this situation, the picture of the net mixed layer-thermocline exchange is a good representation of the ventilation process. However, if the subducted water is exported away from the downwelling region by a circulation branch, then each hotspot can ventilate the thermocline even if the net mixed layer-thermocline exchange along the circumpolar belt shows no net subduction. The pathway of particles in the interior needs to be taken into account in studying the ventilation process. In the following we tackle the issue of ventilated particle pathway, descriptively, by examining tracers and circulation patterns on density surfaces.

\section{c. Interior structure}

The circulation patterns on isoneutral surfaces are compared to observations of PV in the Southern Ocean in Figs. 11 and 12. Five density surfaces spanning the SAMW and AAIW density class are considered: 26.9, $27,27.1,27.2$, and $27.3 \gamma_{n}$ (corresponding, in the mixed layer, to approximately $26.8,26.9,27,27.1$, and $27.2 \sigma_{\theta}$ ). On each of these isopycnals, we observe PV distributions suggestive of branches of circulation leaving the core of the ACC to circulate in the subtropical gyres. We expect them to be essential to the ventilation process in any place where they coincide with hotspots of mixed layer-thermocline exchange. Mixed layer waters are generally associated with low PV compared to water in the interior. Therefore, we expect a reduction of PV on a density surface where the subduction rate is large since (a)

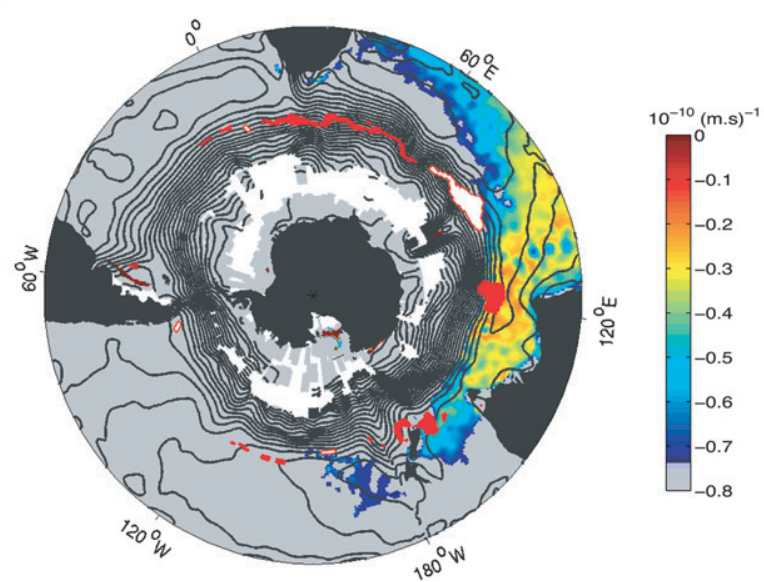

(b)
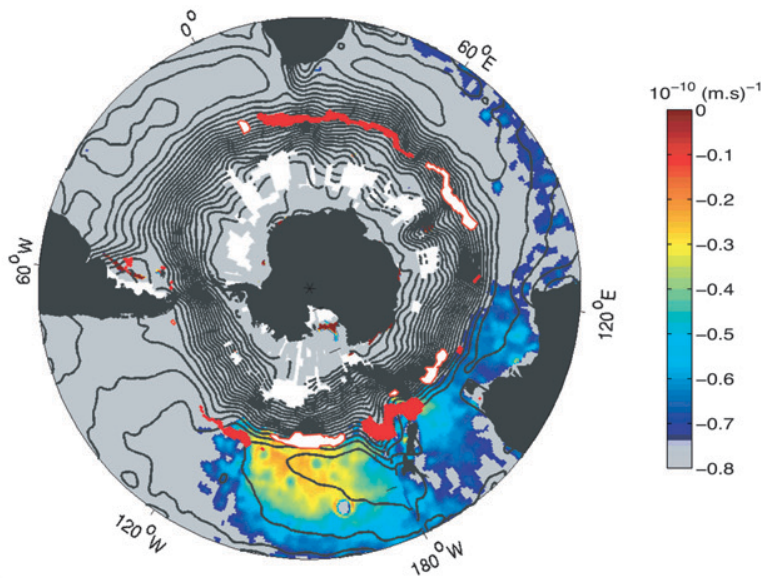

(c)

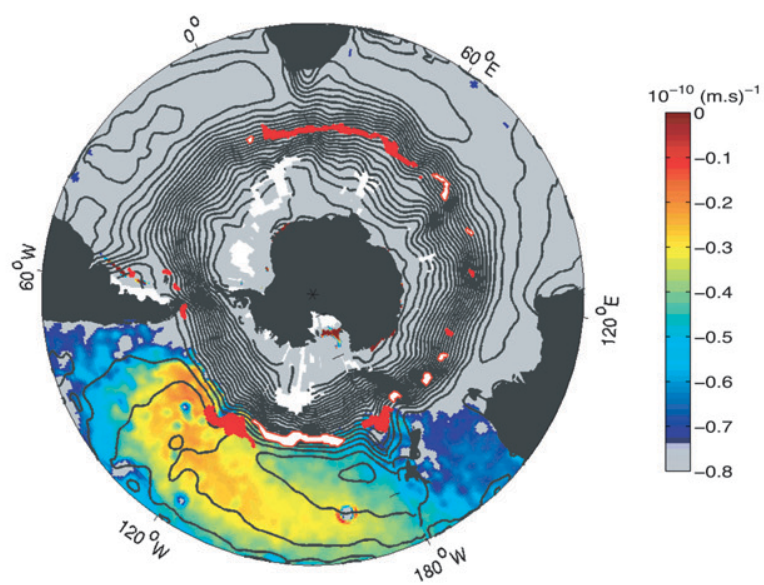

FIG. 11. Interior PV structure on the isoneutral surfaces (a) $26.9 \gamma_{n}$, (b) $27 \gamma_{n}$, and (c) $27.1 \gamma_{n}$. The potential density of the outcrop edge of each surfaces are indicated $\left(\sigma_{\theta \mathrm{ML}}\right)$. Contours of the Montgomery streamfunction on each of the three isopycnals are superimposed. Red patches show the maximum subduction hotspots on each of the isopycnals. White patches encircled by a red line show maximum upwelling hotspots. 
(a)

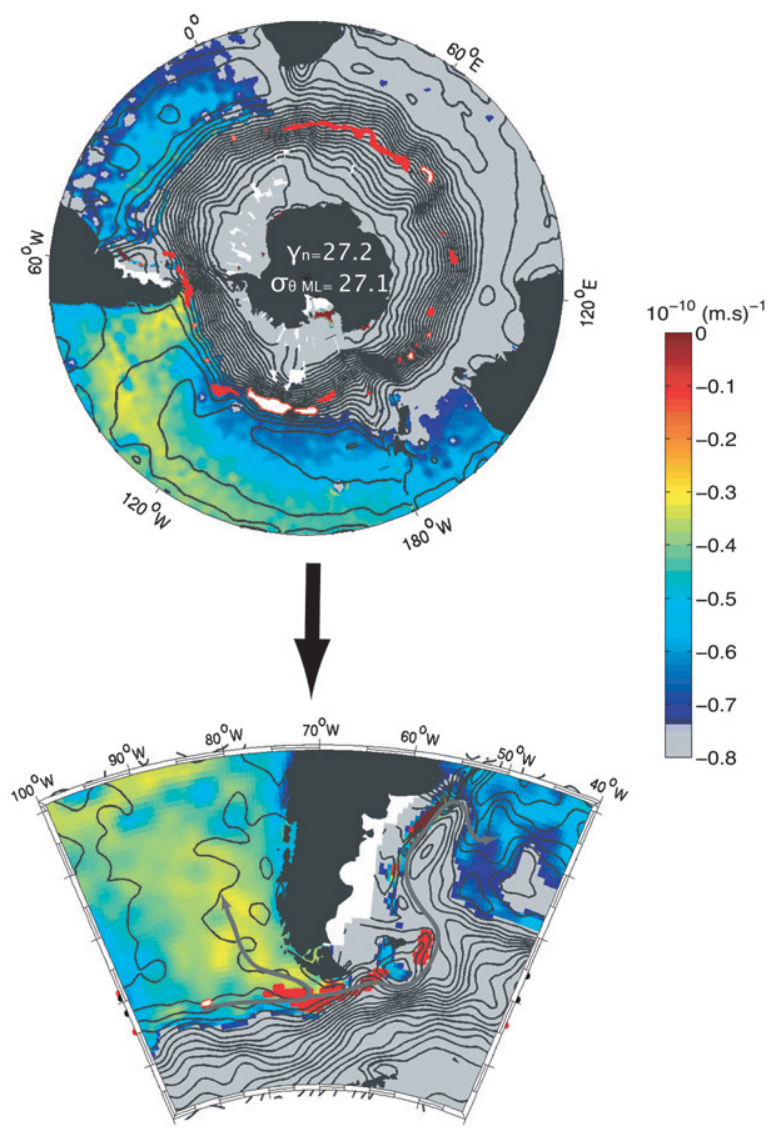

(b)

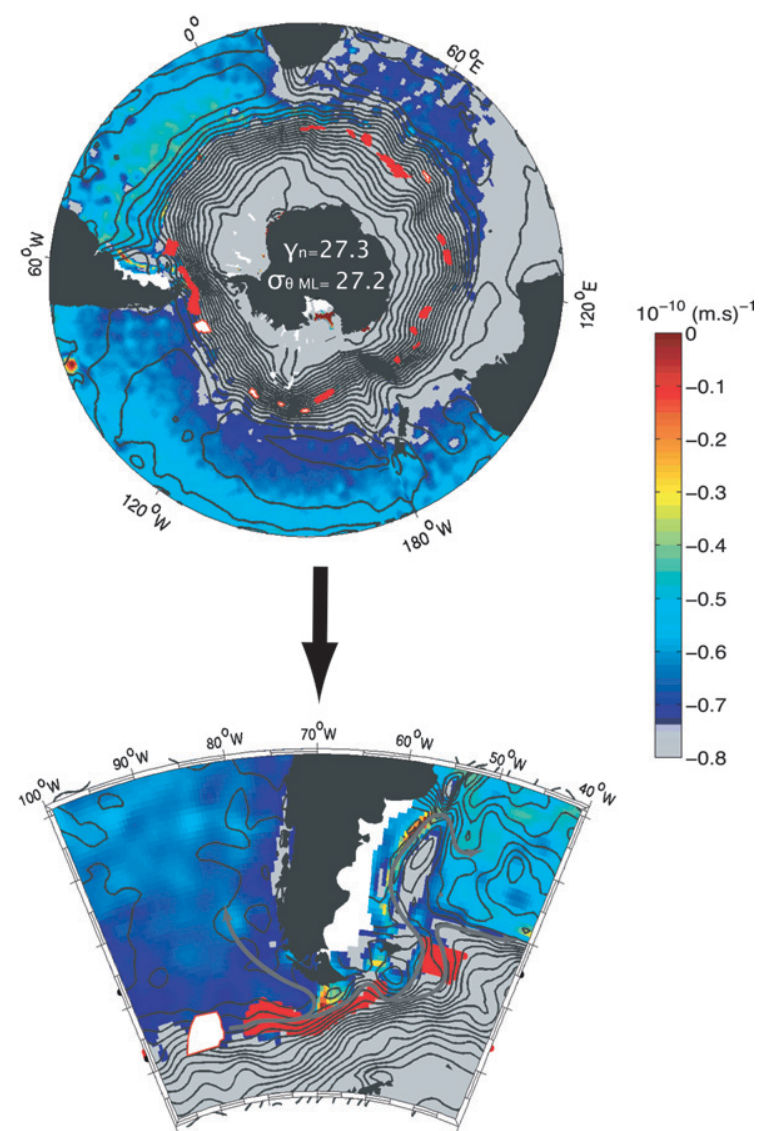

FIG. 12. As in Fig. 11, but for the isoneutral surfaces (a) $27.2 \gamma_{n}$ and (b) $27.3 \gamma_{n}$. Expanded view around Drake Passage is also displayed.

the interior is receiving large volumes of low PV water. Water may also leave the mixed layer along more stratified isopycnals; however, the rate is normally slower since the isopycnal layers are thin.

The western Indian Ocean, south of Africa, is a region of large mixed layer-thermocline exchanges in the SAMW and AAIW density classes but with little consequence. In this region, for each of the densities considered, water subducts in the strong eastward flow of the ACC (red dots south of Africa in Figs. 11 and 12). The water downwelled in this region is not exported away from the base of the mixed layer but this water is reabsorbed back into the mixed layer in upwelling areas downstream, near the Kerguelen Plateau.

The eastern Indian Ocean is a strong hotspot of subduction in the $26.8 \sigma_{\theta}$ (respectively, $26.9 \gamma_{n}$ ). According to Fig. 11, this hotspot coincides with flow toward the subtropical gyre. Indeed, south of Australia, a branch of circulation leaves the ACC core and loops back in the eastern Indian Ocean to circulate in the south Indian subtropical gyre. The PV structure is in good agreement with these observations. First, we observe a strong re- duction of PV right at the location of the subduction hotspot, and second, the PV minimum created is exported away in the South Indian gyre through this exchange window. A smaller part is exported eastward.

The western Pacific Ocean is bounded by two sharp bathymetric features: the Campbell Plateau and the Eltanin Fracture Zone. As seen earlier, these two features affected the subduction pattern on the isopycnals 26.9 and $27 \sigma_{\theta}$ (respectively, 27 and $27.1 \gamma_{n}$ ). Large mass fluxes are found in the western Pacific south of New Zealand on these two isopycnals (consistent with Toggweiler et al. 1989). For both $26.9 \sigma_{\theta}$ and $27 \sigma_{\theta}$, PV is also strongly reduced near the Eltanin Fracture Zone. Indeed, on $26.9 \sigma_{\theta}$ there is a hotspot of downwelling slightly to the west of the Eltanin Fracture Zone. A branch of northward recirculation advects subducted water in a gyre circulation. On $27 \sigma_{\theta}$ the strong downwelling is slighly shifted to the east. This subduction forms a minimum of PV that is advected in the South Pacific subtropical gyre.

Denser layers are much more stratified (Fig. 12). However, we still observe a minimum of PV spreading in the Pacific basin from an area near Drake Passage. As 
seen earlier, Drake Passage is the location of a subduction maximum on these layers. Interestingly, the circulation enters the area south of the tip of South America and then comes back westward in the eastern Pacific, advecting the low PV northward along the coast of Chile before recirculating in the gyre. This is consistent with previous studies that identified this branch of circulation in AAIW layers from observational data (Suga and Talley 1995; Iudicone et al. 2007). The water entering Drake Passage on the surface $27.2 \sigma_{\theta}\left(27.3 \gamma_{n}\right)$ is very stratified compared to lighter layers. However, we still observe a slight reduction of PV. Similar to what happens on 27.1 $\sigma_{\theta}$, a branch of circulation enters the region of large subduction in Drake Passage and goes back into the Pacific basin carrying ventilated water. Directly south of the tip of South America a small closed gyrelike circulation is observed, trapping water of very low PV. However, most of the downwelling occurs in a strong eastward current carrying the recently subducted water into the Atlantic Ocean. We indeed observe a slightly lower PV in the Atlantic basin on this layer.

\section{Conclusions and discussion}

The water mass exchange from the surface layer into the interior has been estimated. The eddy-induced transport in the surface layer makes a large contribution to the transport, carrying $\sim 30 \mathrm{~Sv}$ southward across the ACC fronts. It tends to counterbalance the similarly strong northward Ekman transport within the ACC frontal system. The ACC surface geostrophic flow does not strictly follow isopycnals along its circumpolar path. The subsequent residual meridional circulation consists of $\sim 10 \mathrm{~Sv}$ of upwelling in the layer denser than $27 \sigma_{\theta}$, which is advected toward the north in lighter layers. Approximately $7 \mathrm{~Sv}$ are subducted into dense SAMW (26.8-27 $\sigma_{\theta}$ ), and no consistent downwelling or upwelling is found in the lighter SAMWs $\left(26.6-26.8 \sigma_{\theta}\right)$. The STMWs $\left(26.2-26.6 \sigma_{\theta}\right)$ are fed by northward residual flows as well as by a southward flow, and a total of $14 \mathrm{~Sv}$ are subducted in this layer.

This general structure of the mixed layer-thermocline exchange is not very sensitive to large-scale change of the diffusion coefficient and is consistent with existing air-sea flux products. However, we found strong regional variability, with downwelling and upwelling constrained by bottom bathymetry. The bathymetry steers the circulation, which affects the mixed layer depth distribution, the circulation, and the slope of isopycnals-therefore the subduction. A schematic summary of the subduction process in the Southern Ocean is shown in Fig. 13. Light SAMW downwells mostly in the eastern Indian Ocean and is exported in the southern Indian subtropical gyre.
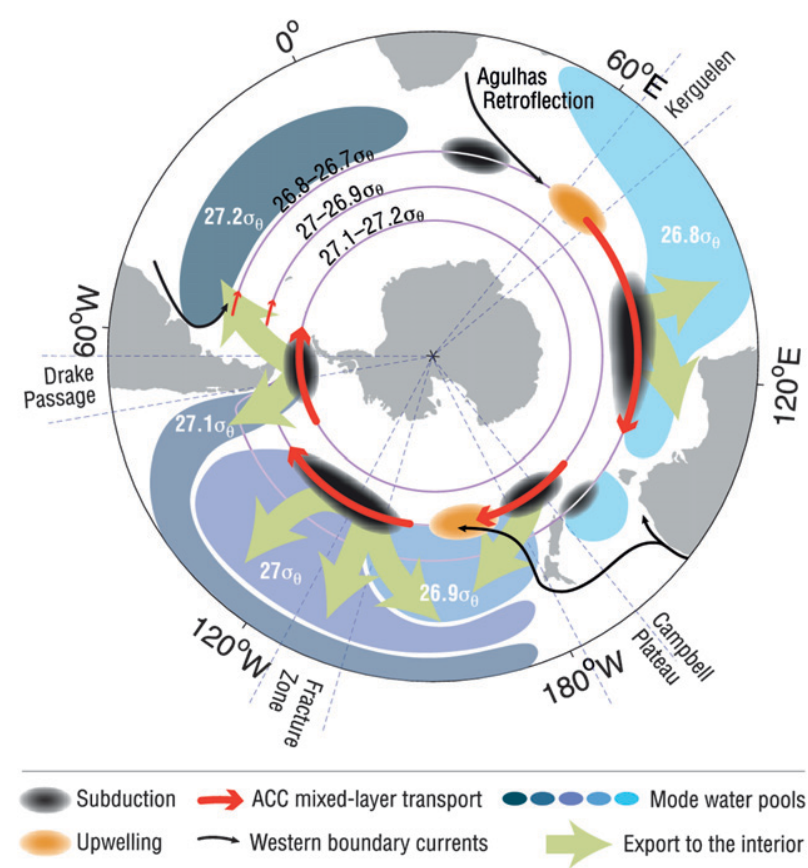

FIG. 13. Schematic showing the intense subduction areas and maximum export areas, along with the SAMW and AAIW in the Southern Ocean.

The ventilation of denser SAMW is concentrated south of the Campbell Plateau and in the central Pacific near the Eltanin Fracture Zone. It is then exported in the South Pacific subtropical gyre, creating two pools of SAMW of $26.9 \sigma_{\theta}$ in the western basin and $27 \sigma_{\theta}$ in the eastern basin. Most of the water in the AAIW density class (27.1-27.2 $\left.\sigma_{\theta}\right)$ subducts in Drake Passage. The light AAIW $\left(27.1 \sigma_{\theta}\right)$ is carried back into the South Pacific subtropical gyre by a regional circulation loop, although the dense AAIW $\left(27.2 \sigma_{\theta}\right)$ is mostly carried away into the Atlantic Basin (Fig. 13).

The rate of subduction implies a time scale for the renewal of mode water of the Southern Ocean within a few decades. This is similar to the renewal rate of mode waters in other oceans. Often tracer distributions are themselves used to infer ventilation rates; the more direct approach here has produced estimates that appear to be consistent with tracer-based values (e.g., Fine et al. 2001; Schlosser et al. 2001). In support of this, oxygen distributions are comparable with the general structure of the subduction hotspots and the interior circulation on each isopycnal. However, we note that the agreement is only limited in some places. Indeed, the spreading of tracers, such as oxygen, is also affected by diffusive eddy contributions that might not be negligible (Jenkins 1987). A detailed agreement with tracer budgets has not been determined here but would be an important further step. 
Karsten and Marshall (2002) found a similar structure of the meridional circulation: a meridional circulation toward the north on the southern, dense side of the ACC and toward the south on the northern, less-dense side. However, they argued that the convergence is in AAIW layers. In this study, we find, instead, the convergence in the denser SAMW layers and also the STMW density classes. Most importantly, we show that the circumpolaraveraged structure hides regional variability and is not representative of the local balances. Sloyan and Rintoul (2001) also found that the northward Ekman transport is largely compensated, suggesting that eddies play a major role in the Southern Ocean meridional circulation. They found a convergence of horizontal flow between the STMW and the AAIW density class in the Atlantic and Indian basin; however, they estimated a circumpolar northward horizontal transport of $34 \mathrm{~Sv}$ in the AAIW, which is more than the $12 \mathrm{~Sv}$ we find in this study. Marsh et al. (2000) parameterized an eddy-induced transport in their model and found a compensation of the northward Ekman transport by eddies. Consistent with our findings, the subduction they infer in their model is at its maximum in the SAMW and is reduced toward the AAIW density class. Finally, Lumpkin and Speer (2007) estimated an upwelling in layers denser than 27 and a subduction of SAMW water, using a global inverse model, consistent with our results.

The estimates proposed in this study are a first step in calculating the impact of eddies on the surface residual circulation from observations. However, we consider only the mesoscale and use a parameterization that could be an inappropriate representation of the full complexity of the mesoscale transport in the ocean (Hallberg and Gnanadesikan 2006; Böning et al. 2008; Screen et al. 2009). Recent studies have shown that smaller, submesoscale eddies could have a great impact on the transfer between the surface layer and interior ocean (Paci et al. 2005; Lapeyre and Klein 2006; Thomas et al. 2010). Their role as mixing processes or transport is not known. In addition, we neglected ventilation by diffusive processes at the base of the mixed layer, which have an impact on tracers (Joyce et al. 1998) and presumably affect the PV flux, hence mass flux as well. A more complete understanding of these small scales and their role in the overall meridional circulation structure would lead to a better representation of the full ventilation process and a better grasp of the impact of recent changes observed in the Southern Ocean (Gille 2002; Morrow et al. 2008; Böning et al. 2008).

Acknowledgments. Louise Bell kindly helped to draw the schematic showing the intense areas of subduction. KS received support from NSF OCE-0822075, OCE-0612167, and OCE-0622670. JBS was supported by a CSIRO Office of the Chief Executive (OCE) Postdoctoral Fellowship. SR was supported by the Australian Government's Cooperative Research Centre's Programme through the Antarctic Climate and Ecosystems Cooperative Research Centre (ACE-CRC). JBS, SR, and SW were also supported by the CSIRO Wealth from Oceans National Research Flagship.

\section{REFERENCES}

Abernathey, R., J. Marshall, M. Mazloff, and E. Shuckburgh, 2010: Enhancement of mesoscale eddy stirring at steering levels in the Southern Ocean. J. Phys. Oceanogr., 40, 170-184.

Böning, C. W., A. Dispert, M. Visbeck, M. Rintoul, and F. Schwarzkopf, 2008: Antarctic circumpolar current response to recent climate change. Nat. Geosci., 1, 864-869.

Chelton, D. B., M. Schlax, M. Freilich, and R. Millif, 2004: Satellite measurements reveal persistent small-scale features in ocean winds. Science, 303, 978-983.

Cisewski, B., V. Strass, and H. Prandke, 2005: Upper-ocean vertical mixing in the Antarctic Polar Front Zone. Deep-Sea Res. II, 52, 1087-1108.

Cushman-Roisin, B., 1987: Subduction. Dynamics of the Oceanic Surface Mixed Layer: Proc. 'Aha Huliko'a Hawaiian Winter Workshop, Honolulu, HI, University of Hawaii at Manoa, 181-196.

Danabasoglu, G., and J. Marshall, 2007: Effects of vertical variations of thickness diffusivity in an ocean general circulation model. Ocean Modell., 18, 122-141.

de Boyer Montégut, C., G. Madec, A. Fischer, A. Lazar, and D. Iudicone, 2004: Mixed layer depth over the global ocean: An examination of profile data and a profile-based climatology. J. Geophys. Res., 109, C12003, doi:10.1029/ 2004JC002378.

Dong, S., J. Sprintall, S. Gille, and L. Talley, 2008: Southern Ocean mixed- layer depth from Argo float profiles. J. Geophys. Res., 113, C06013, doi:10.1029/2006JC004051.

Ferreira, D., J. Marshall, and P. Heimbach, 2005: Estimating eddy stresses by fitting dynamics to observations using a residual mean ocean circulation model and its adjoint. J. Phys. Oceanogr., 35, 1891-1910.

Fine, R. A., K. A. Maillet, K. F. Sullivan, and D. Willey, 2001: Circulation and ventilation flux of the Pacific Ocean. J. Geophys. Res., 106 (C10), 22 159-22 178.

Follows, M. J., and J. C. Marshall, 1994: Eddy-driven exchange at ocean fronts. Ocean Modell., 102, 5-9.

Gent, P., and J. McWilliams, 1990: Isopycnal mixing in ocean circulation models. J. Phys. Oceanogr., 20, 150-155.

Gille, S. T., 2002: Warming of the Southern Ocean since the 1950s. Science, 295, 1275-1277.

- 2003: Float observations of the Southern Ocean. Part I: Estimating mean fields, bottom velocities, and topographic steering. J. Phys. Oceanogr., 33, 1167-1181.

Grist, J. P., and S. A. Josey, 2003: Inverse analysis adjustment of the SOC air-sea flux climatology using ocean heat transport constraints. J. Climate, 16, 3274-3295.

Hallberg, R., and A. Gnanadesikan, 2006: The role of eddies in determining the structure and response of the wind-driven Southern Hemisphere overturning: Results from the Modeling Eddies in the Southern Ocean (MESO) Project. J. Phys. Oceanogr., 36, 2232-2252. 
Hanawa, K., and L. Talley, 2001: Mode waters. Ocean Circulation and Climate, G. Siedler et al., Eds., International Geophysics Series, Vol. 77, Academic Press, 373-386.

Huang, R. X., 1991: The three-dimensional structure of wind-driven gyres: Ventilation and subduction. Rev. Geophys., 29 (Suppl.), 590-609.

Iudicone, D., K. Rodgers, R. Schopp, and G. Madec, 2007: An exchange window for the injection of Antarctic Intermediate Water into the South Pacific. J. Phys. Oceanogr., 37, 31-49.

Jenkins, W. J., 1982: On the climate of a subtropical gyre: Decadal timescale variations in water mass renewal in the Sargasso Sea. J. Mar. Res., 40, 265-290.

— 1987: $3 \mathrm{H}$ and $3 \mathrm{He}$ in the Beta Triangle: Observations of gyre ventilation and oxygen utilization rates. J. Phys. Oceanogr., 17, 763-783.

Joyce, T. M., and W. J. Jenkins, 1993: Spatial variability of subducting water in the North Atlantic: A pilot study. J. Geophys. Res., 98 (C6), 10 111-10 124.

— J. R. Luyten, A. Kubryakov, F. B. Bahr, and J. S. Pallant, 1998: Meso- to large-scale structure of subducting water in the subtropical gyre of the eastern North Atlantic Ocean. J. Phys. Oceanogr., 28, 40-61.

Karsten, R., and J. Marshall, 2002: Constructing the residual circulation of the ACC from observations. J. Phys. Oceanogr., 32, 3315-3327.

Karstensen, J., and D. Quadfasel, 2002: Formation of Southern Hemisphere thermocline waters: Water mass conversion and subduction. J. Phys. Oceanogr., 32, 3020-3038.

Lapeyre, G., and P. Klein, 2006: Dynamics of the upper oceanic layers in terms of surface quasigeostrophic theory. J. Phys. Oceanogr., 36, 165-176.

Ledwell, J., A. Watson, and C. Law, 1998: Mixing of a tracer in the pycnocline. J. Geophys. Res., 103 (C10), 21 499-21 529.

Levitus, S., J. I. Antonov, T. P. Boyer, and C. Stephens, 1998: Warming of the world. Ocean. Sci., 287, 2225-2229.

Lumpkin, R., and K. Speer, 2007: Global ocean meridional overturning. J. Phys. Oceanogr., 37, 2550-2562.

Luyten, J., J. Pedlosky, and H. Stommel, 1983: The ventilated thermocline. J. Phys. Oceanogr., 13, 292-309.

Marsh, R., A. Nurser, A. Megann, and A. New, 2000: Water mass formation in the Southern Ocean in a global isopycnal coordinate GCM. J. Phys. Oceanogr., 30, 1013-1045.

Marshall, D., 1997: Subducting of water masses in an eddying ocean. J. Mar. Res., 55, 201-222.

—, and J. Marshall, 1995: On the thermodynamics of subduction. J. Phys. Oceanogr., 25, 138-151.

Marshall, J., and T. Radko, 2003: Residual mean solutions for the Antarctic Circumpolar Current and its associated overturning circulation. J. Phys. Oceanogr., 33, 2341-2354.

— A. Nurser, and R. Williams, 1993: Inferring the subduction rate and period over the North Atlantic. J. Phys. Oceanogr., 23, 1315-1329.

— D. Jamous, and J. Nilsson, 1999: Reconciling thermodynamic and dynamic methods of computation of water mass transformation rates. Deep-Sea Res. II, 46, 545-572.

- - H. Jones, R. Karsten, and R. Wardle, 2002: Can eddies set ocean stratification? J. Phys. Oceanogr., 32, 26-38.

—_, E. Shuckburgh, H. Jones, and C. Hill, 2006: Estimates and implications of surface eddy diffusivity in the Southern Ocean derived from tracer transport. J. Phys. Oceanogr., 36, $1806-1821$.

McDougall, T. J., 1989: Streamfunctions for the lateral velocity vector in a compressible ocean. J. Mar. Res., 47, 267-284.
- 1991: Parameterizing mixing in inverse models. Dynamics of Oceanic Internal Gravity Waves: Proc. Sixth. 'Aha Huliko'a Hawaiian Winter Workshop, P. Müller and D. Henderson, Eds., Honolulu, HI, University of Hawaii at Manoa, 355-386.

Montgomery, R., 1937: A suggested method for representing gradient flow in isentropic surfaces. Bull. Amer. Meteor. Soc., 18, 210.

Morrow, R., G. Valladeau, and J. Sallée, 2008: Observed subsurface signature of Southern Ocean decadal sea level rise. Prog. Oceanogr., 77, 351-366.

Naveira-Garabato, A. C., J. Allen, H. Leach, V. Strass, and R. Pollard, 2001: Mesoscale subduction at the Antarctic Polar Fron driven by baroclinic instability. J. Phys. Oceanogr., 31, 2087 2107.

Paci, A., G. Caniaux, M. Gavart, H. Giordani, M. Levy, L. Prieur, and G. Reverdin, 2005: A high-resolution Simulation of the ocean during the POMME experiment: Simulation results and comparison with observations. J. Geophys. Res., 110, doi:10.1029/ 2004JC002712.

Qiu, B., and R. Huang, 1995: Ventilation of the North Atlantic and North Pacific: Subduction versus obduction. J. Phys. Oceanogr., 25, 2374-2390.

Rhines, P. B., and W. R. Young, 1982: Homogenization of potential vorticity in planetary gyres. J. Fluid Mech., 122, 347-367.

Ridgway, K., J. Dunn, and J. Wilkin, 2002: Ocean interpolation by four-dimensional weighted least squares-Application to the waters around Australasia. J. Atmos. Oceanic Technol., 19, 1357-1375.

Rintoul, S., and M. England, 2002: Ekman transport dominates airsea fluxes in driving variability of subantarctic mode water. $J$. Phys. Oceanogr., 32, 1308-1321.

Rio, M., P. Schaeffer, F. Hernandez, and J. Lemoine, 2005: The estimation of the ocean mean dynamic topography through the combination of altimetric data, in-situ measurements and GRACE geoid: From global to regional studies. Proc. GOCINA Int. Workshop, Luxembourg, Geoid and Ocean Circulation in the North Atlantic, 171-177.

Robbins, P. E., J. Price, W. B. Owens, and W. Jenkins, 2000: The importance of lateral diffusion for the ventilation of the lower thermocline in the subtropical North Atlantic. J. Phys. Oceanogr., 30, 67-89.

Robinson, A. R., and H. Stommel, 1959: The oceanic thermocline and the associated thermohaline circulation. Tellus, 11, 295-308.

Rupolo, V., 2007: A Lagrangian-based approach for determining trajectories taxonomy and turbulence regimes. J. Phys. Oceanogr., 37, 1584-1609.

Sallée, J., N. Wienders, R. Morrow, and K. Speer, 2006: Formation of Subantarctic Mode Water in the southeastern Indian Ocean. Ocean Dyn., 56, 525-542, doi:10.1007/s10236-0050054-x.

$\longrightarrow$, R. Morrow, and K. Speer, 2008a: Eddy diffusion and Subantarctic Mode Water formation. Geophys. Res. Lett., 35, L05607, doi:10.1029/2007GL032827.

—, K. Speer, and R. Morrow, 2008b: Response of the Antarctic Circumpolar Current to atmospheric variability. J. Climate, 21, 3020-3039.

$\ldots,-\ldots$, and R. Lumpkin, 2008c: An estimate of Lagrangian eddy statistics and diffusion in the mixed layer of the Southern Ocean. J. Mar. Res., 66, 441-463.

Sarmiento, J., 1983: A tritium box model of the North Atlantic thermocline. J. Phys. Oceanogr., 13, 1269-1274.

Schlosser, P., J. Bullister, R. Fine, W. Jenkins, R. Key, J. Lupton, W. Roether, and W. Smethie, 2001: Transformation and age of 
water masses. Ocean Circulation and Climate: Observing and Modelling the Global Ocean, G. Siedler et al., Eds., International Geophysics Series, Vol. 77, Academic Press, 427-450.

Screen, J., N. Gillett, D. Stevens, G. Marshall, and H. Roscoe, 2009: The role of eddies in the Southern Ocean tempereature response to the Southern Annular Mode. J. Climate, 22, 806-818.

Shuckburgh, E., E. Jones, J. Marshall, and C. Hill, 2009: Understanding the regional variability of eddy diffusivity in the Pacific sector of the Southern Ocean. J. Phys. Oceanogr., 39, 2011-2023.

Sloyan, B., and S. Rintoul, 2001: Circulation, renewal, and modification of Antarctic Mode Water and Intermediate Water J. Phys. Oceanogr., 31, 1005-1030.

Smith, K. S., and J. Marshall, 2009: Evidence for deep eddy mixing in the Southern Ocean. J. Phys. Oceanogr., 39, 50-69.

Sorensen, J., J. Ribbe, and G. Shaffer, 2001: On Antarctic Intermediate Water mass formation in general circulation models. J. Phys. Oceanogr., 31, 77-91.

Speer, K., and E. Tziperman, 1992: Rates of water mass formation in the North Atlantic Ocean. J. Phys. Oceanogr., 22, 93-104.

_ S. R. Rintoul, and B. M. Sloyan, 2000: The diabatic Deacon cell. J. Phys. Oceanogr., 30, 3212-3222.

Suga, T., and L. D. Talley, 1995: Antarctic Intermediate Water circulation in the tropical and subtropical South Atlantic. J. Geophys. Res., 100 (C7), 13 441-13 453.

Sundermeyer, M. A., and J. Price, 1998: Lateral mixing and the North Atlantic Tracer Release Experiment: Observations and numerical simulations of Lagrangian particles and a passive tracer. J. Geophys. Res., 103 (C10), 21 481-21 497.
Thomas, L., C. Lee, and Y. Yoshikawa, 2010: The subpolar Front of the Japan/East Sea. Part II: Inverse method for determining the frontal vertical circulation. J. Phys. Oceanogr., 40, 3-25.

Toggweiler, J. R., K. Dixon, and K. Bryan, 1989: Simulations of radiocarbon in a coarse-resolution World Ocean Model. 2. Distributions of bomb-produced carbon 14. J. Geophys. Res., 94 (C6), 8243-8264.

Treguier, A., I. Held, and V. Larichev, 1997: Parameterization of quasigeostrophic eddies in primitive equation ocean model. J. Phys. Oceanogr., 27, 567-580.

—, M. England, S. Rintoul, G. Madec, J. Le Sommer, and J. Molines, 2007: Upper-ocean meridional circulation in a numerical model of the Antarctic Circumpolar Current. Ocean Sci., 4, 653-698.

Vivier, F., D. Iudicone, F. Busdraghi, and Y.-H. Park, 2010: Dynamics of sea surface temperature anomalies in the Southern Ocean diagnosed from a 2-D mixed layer model. Ocean Modell., 40, 3-25.

Welander, P., 1959: An advective model of the ocean thermocline. Tellus, 11, 309-318.

Woods, J. D., 1985: The physics of thermocline ventilation. Coupled Ocean-Atmosphere Models, J. C. J. Nihoul, Ed., Elsevier Oceanography Series, Vol. 40, Elsevier, 543-590.

Zhurbas, V., and I. Oh, 2004: Drifter-derived maps of lateral diffusivity in the Pacific and Atlantic Oceans in relation to surface circulation patterns. J. Geophys. Res., 109, C05015, doi:10.1029/2003JC002241. 